\title{
The Disclosure Experiences of Male Child Sexual Abuse Survivors
}

Submitted by: Charlotte GagnierSupervised by: Dr. Delphine Collin-Vézina School of Social Work, McGill University, Montreal, June, 2014

A thesis submitted to McGill University in partial fulfillment of the requirements of the degree of Master's in Social Work (MSW)

(C) Charlotte Gagnier 2014 


\begin{abstract}
:
Objectives: This thesis explores the diversity in the disclosure process of male survivors of child sexual abuse (CSA).

Background: The literature generally focuses on female victims of CSA overlooking the needs and the reality of male victims. While rates are difficult to ascertain it is generally believed that around $10 \%$ of men have been abused sexually as children. Disclosure is a complex process for victims of both genders, however masculine norms and stereotypes contribute to an environment that negates men's experiences.

Method: A combination of two qualitative methodologies, the phenomenological approach and the interpretive descriptions method were used to complete a secondary analysis of telephone interviews conducted with seventeen (17) adult male survivors of CSA.

Results: Although diversity exists in the disclosure experiences of male survivors, both positive and negative disclosure experiences were identified. Trajectories varied from one participant to another, however the majority of the men disclosed for the first time in adulthood. Obtaining professional help proved to be rather challenging for the men due to limited specialized services.
\end{abstract}

Implications: Policies need to change to reflect the reality and needs of male CSA survivors, and increase their social recognition. Services must be made accessible to individuals in order to reduce challenges in getting adequate care.

Conclusion: Male disclosure of CSA should be understood as a multi-faceted and lengthy process. The voice of men must be heard in their own right in order to reduce the stigma felt by this group and develop the tools to offer proper treatment. 


\section{Résumé :}

Objectifs : Ce mémoire explore la diversité dans le processus de dévoilement des hommes victimes d'agression sexuelle (AS) vécue pendant l'enfance.

Contexte : La littérature se concentre généralement sur les femmes victimes d'AS dans l'enfance en passant outre les besoins et la réalité des victimes de sexe masculin. Bien que le nombre de victimes soit difficile à quantifier, il est généralement reconnu que près de $10 \%$ des hommes ont été victimes d'AS dans leur enfance. Le dévoilement est un processus complexe pour les victimes des deux sexes, mais les stéréotypes et les normes liés à la masculinité contribuent à créer un environnement qui nie pratiquement les expériences vécues par les hommes.

Méthode : Une combinaison de deux méthodes qualitatives a été utilisée pour compléter ce mémoire : l'approche phénoménologique et l'approche d'interprétation des descriptions ont été utilisées afin de compléter une analyse secondaire d'entrevues téléphoniques menées auprès de dix-sept (17) adultes de sexe masculin survivants d'AS vécue pendant l'enfance.

Résultats : Bien qu'une importante diversité existe dans l'expérience de dévoilement des victimes masculines, la présence d'expériences à la fois positives et négatives ont été identifiées. La trajectoire varie d'une personne à l'autre, mais la majorité des hommes ont indiqué avoir dévoilé l'agression vécue pour la première fois à l'âge adulte. Obtenir de l'aide professionnelle s'est avéré assez difficile pour les participants en raison de services spécialisés limités.

Implications : Les politiques doivent changer pour refléter la réalité et les besoins des hommes survivants d'AS subie dans l'enfance ainsi que pour augmenter la reconnaissance de ce fléau social. Les services doivent devenir plus accessibles aux hommes afin de réduire les difficultés à obtenir les soins adéquats.

Conclusion : Le dévoilement des hommes survivants d'AS vécue dans l'enfance doit être compris comme un processus multiforme et de longue haleine. La voix des hommes doit être entendue afin de réduire la stigmatisation ressentie par ce groupe et de développer les outils nécessaires pour venir en aide à ce segment de population. 


\section{Acknowledgements}

It is with great joy and emotion that I wish to offer thanks to the people who supported me throughout the completion of my MSW thesis. While at times this project was a roller coaster pulling me in different directions, the road this thesis finally took proved to be extremely fulfilling; it helped teach me the importance of thinking outside the box, and remaining focused.

This thesis would simply not have been possible without the many opportunities that my supervisor Dr. Delphine Collin-Vézina provided. Her knowledge, and expertise proved to be both inspiring and invaluable as she was able to transmit her passion for research. Most of all, it is her optimism, and encouragement that helped me progress, and for that, I thank her.

I would also like to thank my colleagues at the CRCF for inspiring me with their own research endeavors. Special thanks go to David Silva for making me laugh when I wanted to cry and for helping me keep things in perspective, as well as to Mireille De La Salblonière-Griffin for her incredible generosity with regards to her time throughout the various phases of my thesis, and to Stéphanie Pelletier for always encouraging me.

To my father, Robert Robson, I must extend my deepest gratitude as he has rooted for me from the beginning, and has always been available to help me in every possible way. Special thanks must also go to Pat Strachan who not only pushed me to work through my challenges but also allowed me to learn a great deal from her expertise in the field of qualitative research.

Words cannot express the gratitude I feel towards my husband Elie, who supported me unconditionally throughout all the phases of my studies, and held the pieces of our lives together when I simply could not.

Finally, I wish to offer sincere thanks to the men who shared their personal narratives of disclosure; without them this thesis would not have been possible. 


\section{Contents}

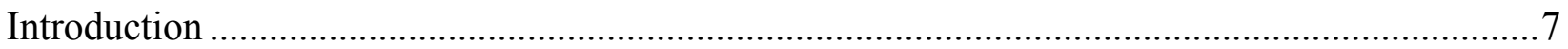

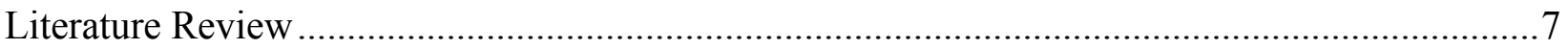

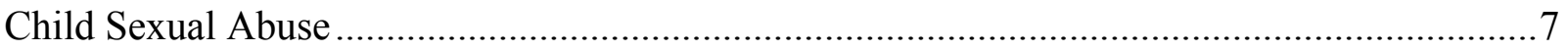

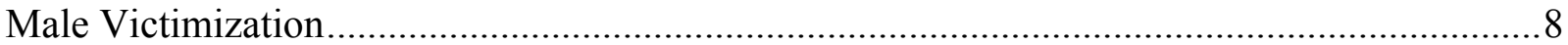

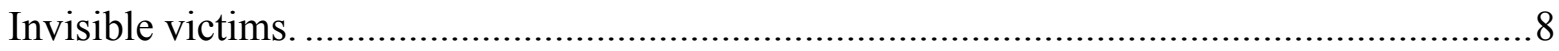

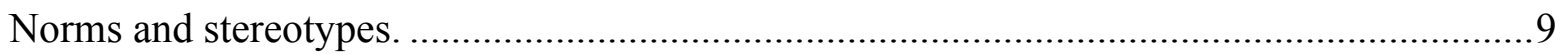

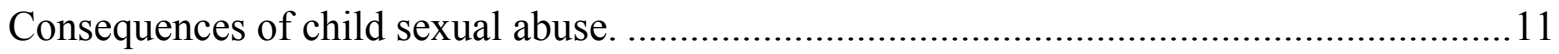

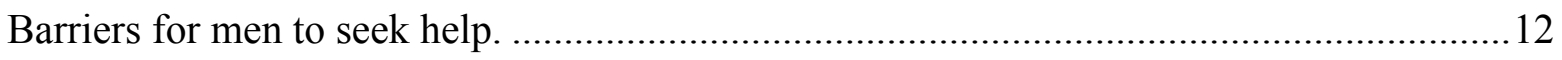

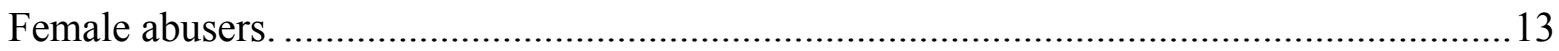

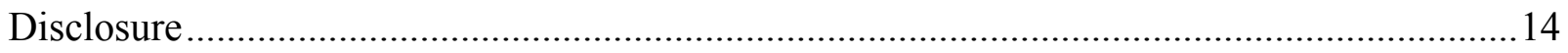

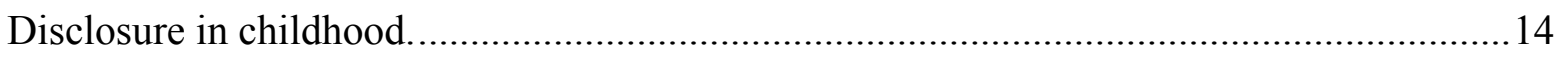

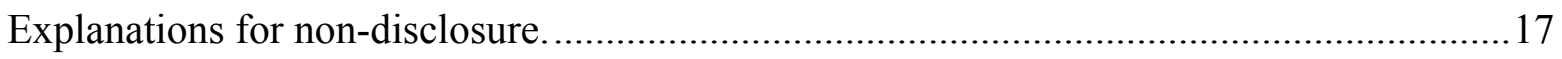

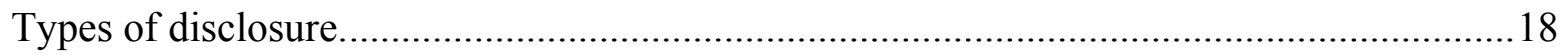

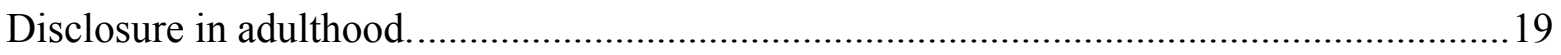

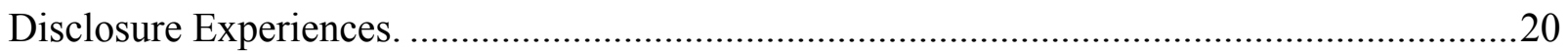

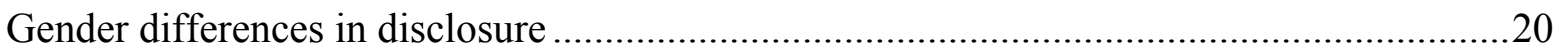

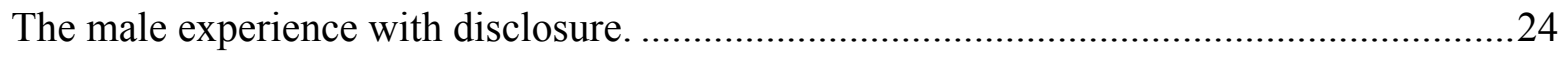

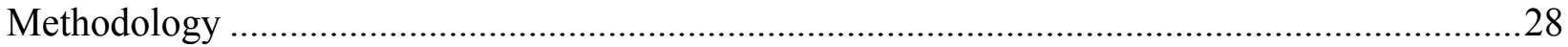

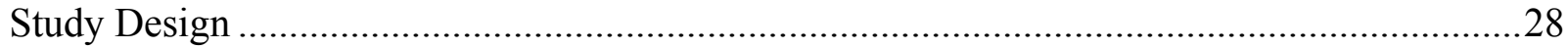

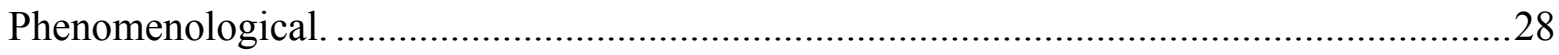

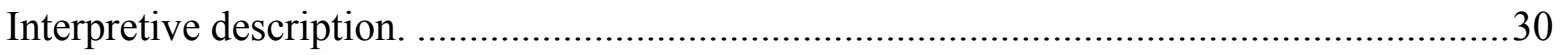

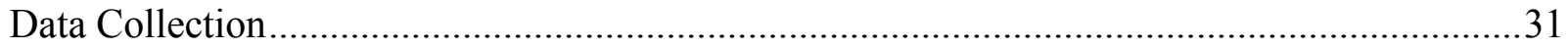

The use of telephone interviews in research. ...................................................................

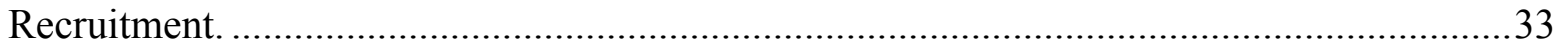

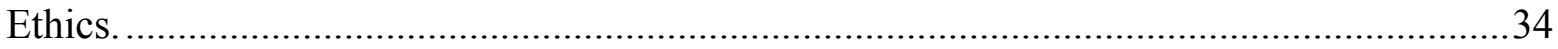

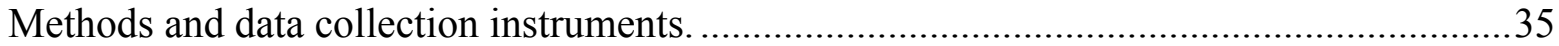

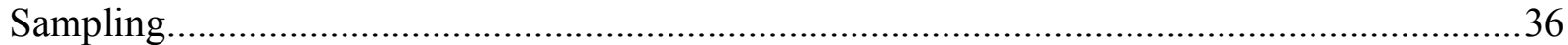

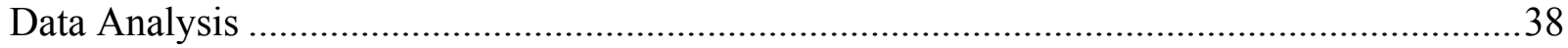

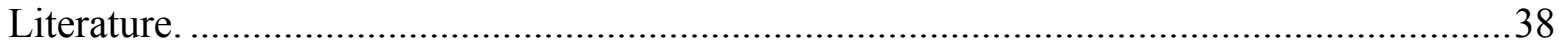

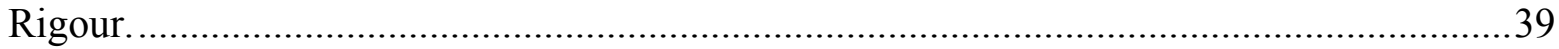

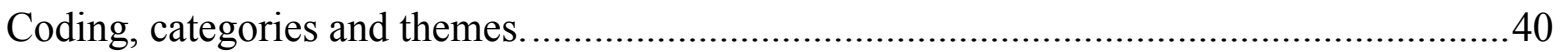

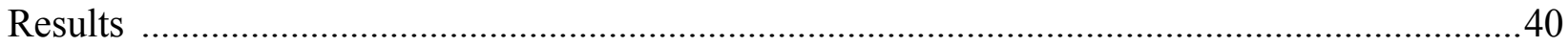

Impact of the Abuse on Various Spheres the Men's Lives ........................................................41 


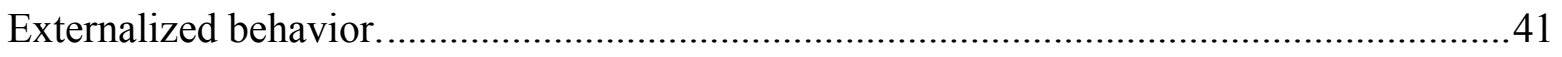

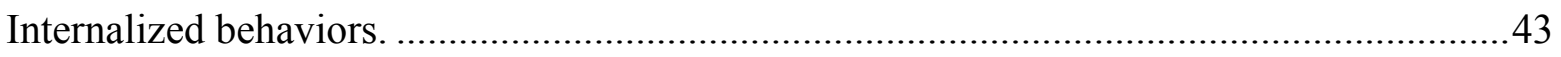

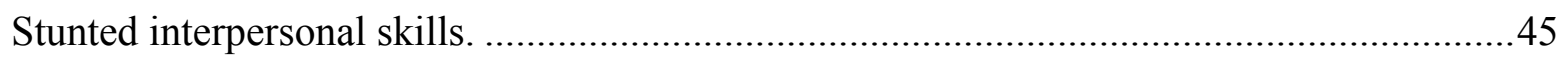

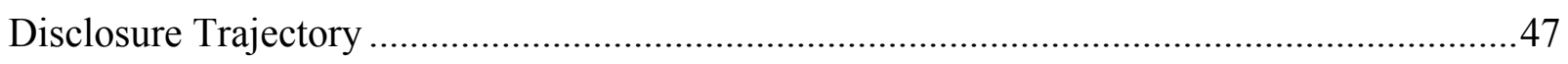

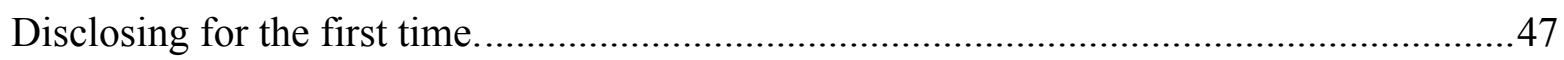

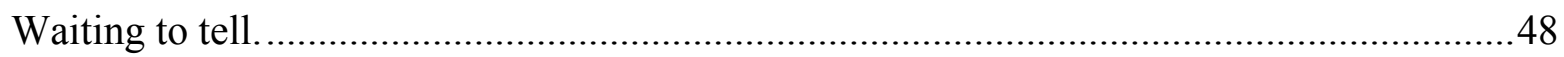

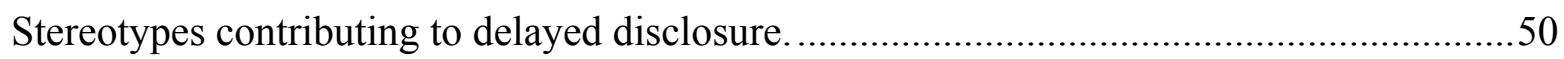

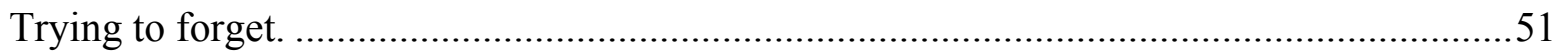

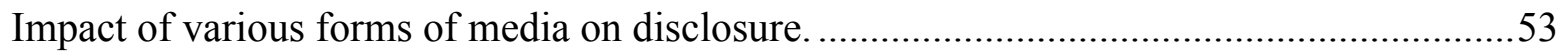

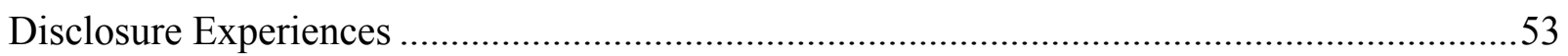

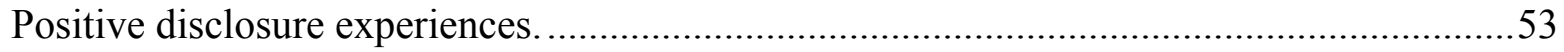

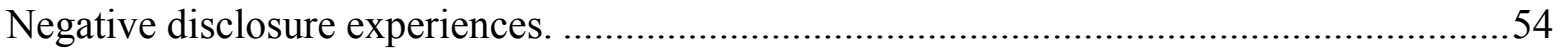

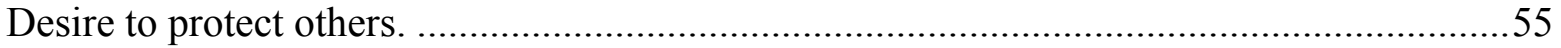

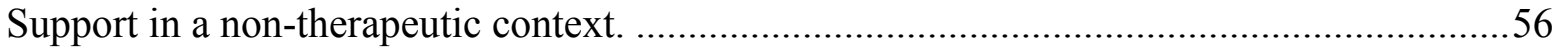

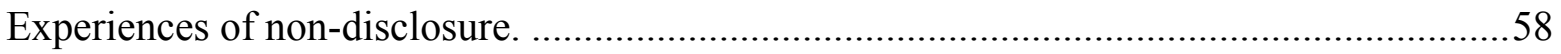

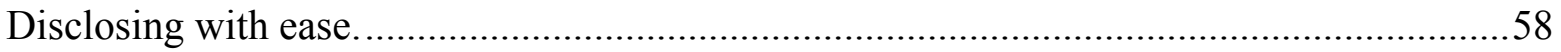

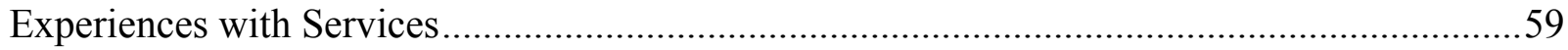

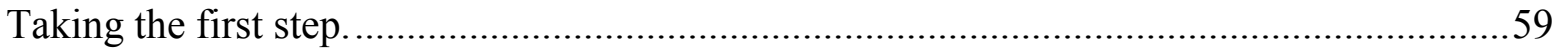

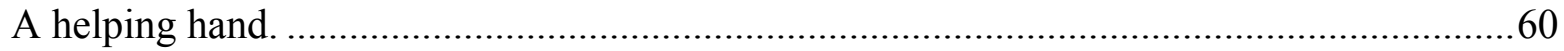

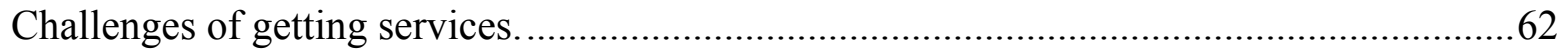

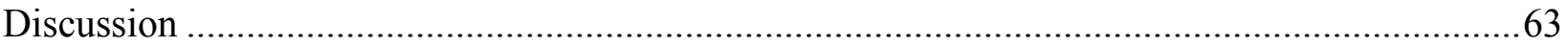

Impact of the Abuse on Various Spheres of the Men's Lives..................................................63

Externalized behavior....................................................................................................6

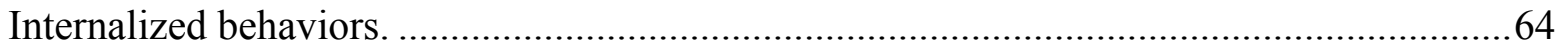

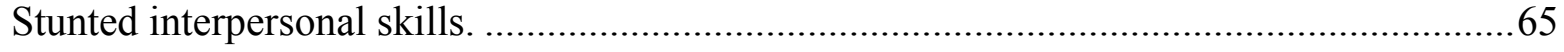

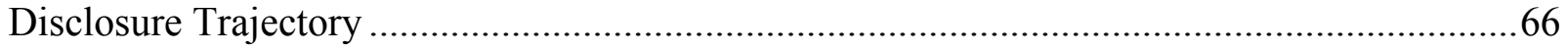

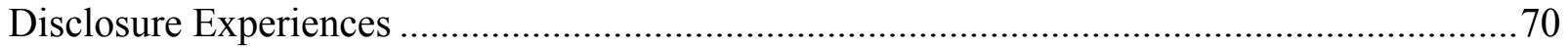

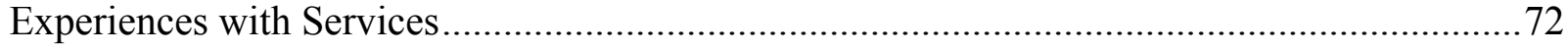

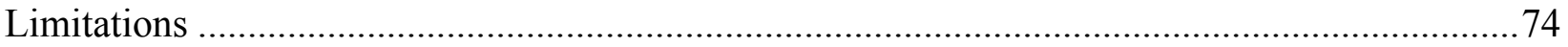

Future Research Opportunities.......................................................................................

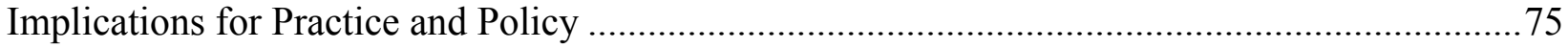

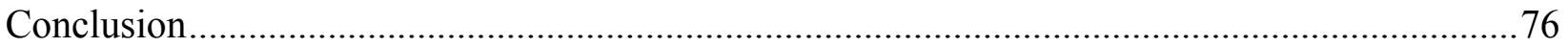

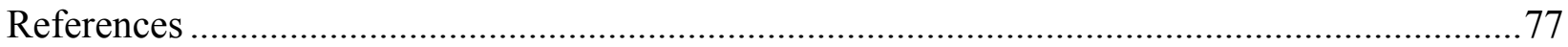




\section{Introduction}

Sexual abuse runs across gender, geographic and racial lines, it affects individuals of all ages and impacts many different spheres of their lives. While girls are often believed to be the obvious victims in cases of child sexual abuse (CSA); boys of all ages can also fall victim to the same type of abuse (Alaggia, \& Millington, 2008). Although CSA is starting to get more attention socially, the abuse of boys remains taboo and is often ignored (Anderson, 2011). Disclosing CSA is often a complex and painful step for victims to take, whether they disclosed early on, or later in their adult life (Ahrens, Stansell, \& Jennings, 2010). While disclosure is a challenging process for victims of both sexes, it is made even more difficult for males as they must overcome unreceptive environments that typically adhere to traditional gender norms (Alaggia, 2010). The following thesis will address disclosure of CSA for male victims as a

process, and will seek to identify the diversity that exists in disclosure experiences. The literature regarding male CSA and disclosure will first be thoroughly examined in order to uncover the information already available on the topic. In order to better understand the experiences of male victims' disclosure of abuse, a qualitative analysis of interviews conducted with 17 male survivors of CSA will then be conducted. A phenomenological approach, in conjunction with an interpretive description method will be used to describe the experiences of male victims of CSA and how they have negotiated disclosure.

\section{Literature Review}

\section{Child Sexual Abuse}

It is generally understood in the literature that CSA encompasses any type of sexual activity with a minor by a person in a position of control or authority (Tourigny, \& Baril, 2011). Statistics regarding the sexual abuse of children are difficult to ascertain due to the complex 
nature of the abuse, the manner in which data is collected, as well as the limited number of victims who disclose in a timely manner (Hartill, 2009; Stolenborgh, Van, Ijzendoorm, Euser, \& Bakermans-Kranenburg, 2011); it is nonetheless believed that the numbers are quite staggering.

Stolenborgh, et al. (2011) conducted a thorough meta-analysis of the prevalence of CSA around the world by looking at 217 articles published between 1980 and 2008 . While the statistics fluctuated depending on the sample and methodology used in each article, the authors noted that the prevalence of CSA for girls stood at around 180/1000 (18 percent), and for boys was at 76/1000 (7.6 percent). In a review of the literature concerning the prevalence of CSA (most articles were from North America), Tourigny, and Baril (2011) similarly established that one in ten men, and one in five women disclosed having been sexually abused during the course of their childhood. Statistics for the province of Quebec reflected a similar reality; Hébert, Tourigny, Cyr, McDuff, and Joly (2009) attempted to discover the prevalence of CSA and the disclosure patterns amongst men and women in Quebec. The authors conducted random digit dialing to reach residents of the province and asked them to complete a survey. Of the 804 participants the authors found that $22.1 \%$ of women and $9.7 \%$ of men had been sexually abused as children.

\section{Male Victimization}

Invisible victims. Male victims of CSA are often forgotten and seem almost invisible as their plight is so infrequently discussed (Easton, 2013; Alaggia, \& Mishna, 2014). Society appears to promote the needs of female victims by focusing more attention on them than on male survivors of similar abuse (Dorahy, \& Clearwater, 2012). The feminist movement, which contributed so positively to giving recognition to the issue of rape, violence and sexual abuse of women and children, has also unfortunately helped perpetuate the image that men should be seen 
as abusers, and not victims (Price-Robertson, 2012). Davies and Rogers (2006) further explained that by openly publicizing rape and abuse against women, feminists have inadvertently created an atmosphere in which male victims are either forgotten or ignored. Alaggia and Millington (2008) further noted that while research often seems to focus on cases in which men are abusers and victims are female, the media also contributes to perpetuating this image. Without necessarily realizing the impact it has, the media circulates information to the general population through newspapers and broadcasts supporting the concept that CSA victims are of female gender.

Studies that address CSA generally focus solely on female victims, and when they include men in their samples, the numbers are often so small that their experiences become either overlooked or lumped-in with those of female survivors (Alaggia, \& Millington, 2008; Diamanduros, et al., 2012; Dubé, et al., 2005; Easton, Renner, \& O’Leary, 2013; O’Leary, \& Gould, 2010; Sorsoli, et al., 2008; Ullman, 2003; Valente, 2005). While female victims of CSA are indeed more common than male victims, their experience becomes the norm as the abuse history of men are often ignored by researchers (Price-Robertson, 2012).

Norms and stereotypes. Male survivors face challenges that differ from females, largely in relations to the social stereotypes placed on men and masculinity (Dorahy, \& Clearwater, 2012). Indeed, being sexually abused as children may create serious struggles, for men, in regards to the views placed on their gender. O'Leary and Barber (2008) explained that "negative attitudes towards male victims clearly have the potential to discourage boys from disclosing and men from discussing their experiences as abused children" (p. 136). Men are often seen by our society as being dominant, powerful, even sometimes aggressive; being a victim goes against gender norms and challenges society in what is regarded as weakness (Anderson, 2011; Alaggia, 2010; Conh, \& Zeichner, 2006; Grossman, Kia-Keating, \& Sorsoli, 2006; Sorsoli, et al., 2008; Hunter, 2009). 
Male CSA challenges how masculinity is seen in the western cultures as the norms of masculinity get distorted when we are forced to think of men as victims; Price-Robertson (2012) noted that "since the act of sexual abuse commonly exposes boys to a sexual experience with another male and casts them as vulnerable and passive victims, it places them in a position that is starkly at odds with the dominant construct of masculinity" (p. 138). Gender norms therefore reinforce the tendency for male victims of CSA to blame themselves and feel ashamed of the abuse they suffered as children (Easton, et al., 2013). Alaggia and Millington (2008) further explained that it is difficult for men to disclose or seek treatment because of the social norms and stereotypes regarding masculinity, strength, and power; men are not supposed to be victims; they should not be weak because those are female qualities; in other words "male weakness is associated with feminine traits, something that is devalued in sexist cultures" such as ours (p. 265).

In addition, Kia-Keating, Grossman, Soroli, and Epstein (2005) found that when males are sexually abused there is an underlying assumption, in our society, that they should have been strong enough to fight off the abuse. The authors further explained that due to the notion that men should be able to defend themselves against sexual abuse, those that do not manage to escape it, in some underlying way must have consented, and therefore their sexual orientation is sometimes put into question. Homophobia helps perpetuate an atmosphere of judgment, which only contributes to the shame and invisibility of male victims (Alaggia, 2010; Davies, \& Rogers, 2006; Dorahy, \& Clearwater, 2012; Hunter, 2011; Paine, \& Hansen, 2002; Valente, 2005). Diamanduros, et al. (2012) noted that the invisibility of male victims was fuelled by fears of being seen as weak or as a homosexual since "in our society, males are socialized to be dominant, independent, powerful, aggressive, and authoritarian" (p. 132). Similarly Hunter (2011) explained that male victims feared being labeled as homosexuals so much so that it often caused them 
severe anxiety. Alaggia (2005) also mentioned that concerns regarding homophobic stereotypes in their environment led victims, in her sample, to show major concerns regarding their sexual orientation: "the experience of being abused by a same-sex perpetrator strongly shaped the men's experiences about their sexual orientation (were they gay or not?) and factored in to reasons for not telling" (p. 461).

The social attitudes male victims face, are not solely conveyed by the general public, but also seem to be present in the minds of professionals. O'Leary, and Barber (2008) found that popular stereotypes regarding male CSA survivors often reached the professionals working with them, causing them sometimes to help silence the victims by perpetuating the notion that they should have been able to prevent the abuse. Price-Robertson (2012) noted that in some cases, professionals also helped perpetuate the idea that male victims of CSA matured in to sexual abusers in adulthood. The author found that varied types of literature openly circulated in sexual abuse prevention organizations as well as in government funded offices falsely delivered the message that the transformation from victim to abuser is almost linear.

Consequences of child sexual abuse. CSA has numerous consequences and has long lasting effects on victims throughout their life span, often leaving them with a sense of loss, and stigmatization (Alaggia, 2005; Easton, 2013). The consequences of CSA often continue well into adulthood affecting nearly all facets of victims' lives ranging from lower socioeconomic outcomes, PTSD, depression, anxiety, use of illicit drugs or alcohol, self-mutilation, and increased risk of suicide attempts (Currie, \& Spatz Widom, 2010; Denov, 2004; Dube et al. 2005; Fergusson, McLeod, \& Horwood, 2013; O’Leary, \& Gould, 2010; Ullman, 2003; Valente, 2005; Hunter, 2009). 
Although several similarities exist between male and female CSA victims, gender differences continue to be noted in children as well as in adults. The effects of CSA seem to manifest themselves slightly differently depending on the gender of the victim, as boys have been shown to demonstrate externalized behaviors, while girls are more likely to internalize the behaviors (Hornor, 2010; Muller, \& Dowling, 2008). Similar gender patterns continue in adulthood as men are more likely than women to develop externalized behaviors following CSA, raging from aggressiveness and substance use to criminal behaviors (Sorsoli, Kia-Keating, \& Grossman, 2008). Due to the nature of the abuse, sexually abused children also tend to develop inappropriate notions regarding acceptable or appropriate sexual behaviors (Follette, La Bash, \& Sewell, 2009). In a study on psychosexual functioning of 165 CSA survivors, Easton, Coohey, O’Leary, Zhang, \& Hua (2011) found that sexual problems experienced by victims included: fear and guilt during sexual intercourse; having problems being touched in a sexual way or having difficulty with arousal; and finally being generally unsatisfied with their sexual life. Negative feelings or discomfort related to sexuality were found to be common among CSA survivors of both sexes (Denov, 2004; Ullman, 2003). However, dysfunction and sexual risk-taking were more common in men (Valente, 2005; Deering \& Mellor, 2011). Alaggia and Millington (2008) found that male victims of CSA sometimes demonstrated a great deal of anger and sexual aggression, as well as sexual development issues. The authors noted that some of the men in their study reported various levels of sexual dysfunction ranging from promiscuous behavior to being involved in the pornography industry or working as male prostitutes.

Barriers for men to seek help. Masculine norms affect not only sexually abused men in terms of their identity, but also in terms of their help-seeking behaviors. Indeed, it seems evident that stereotypes surrounding masculinity often lead men to seek psychological and medical help less often than women (Yousaf, Grunfeld, \& Hunter, 2013; Galdas, Cheater, \& Marshall, 2004). 
Men are rarely socialized to be open about their emotional troubles; which in turn was found to contribute to their underutilization of mental health services (Mackenzie, Gekoski, Knox, 2006). Simply put, "boys are taught to be stoical and to ignore symptoms ("boys don't cry"), the threshold for expressing pain and emotional sensitivity (especially related to emotions like weakness, uncertainty, helplessness, and sadness) is heightened and results in emotional restriction” (Möller-Leimkühler, 2002).

Mahalik, Good, and Englar-Carlson (2003) noted that men are often reluctant to seek help due to popular scripts they learned, which dictate that males are strong enough not to need help. Cleary (2012) similarly explained that typical constructs of masculinity presented men as emotionally strong and stoic individuals, and within the constraints of masculine norms found disclosing psychological concerns especially challenging. Yousaf, et al. (2013) also noted that adhering to traditional gender norms greatly impacted men's ability to seek services and help for emotional or physical issues. The authors noted that embarrassment, anxiety and fears, as well as poor communication with professionals were the most critical barriers to help-seeking for men. The reluctance of men to seek help seems especially pertinent to the field of male CSA research as it demonstrates the power masculine norms and stereotypes can have both on silencing the victims and on preventing them from getting the necessary help.

Female abusers. Although sexual predators are generally believed to only be male, women have also been found to sexually abuse children of both genders (Anderson, 2011; Deering \& Mellor, 2011; Denov, 2004). While Grossman, et al. (2006) noted that men were socialized to be sexually aggressive and in charge of their sexual encounters; it seems that the image of women as perpetrators is a more difficult one for society to accept as their gender is usually seen as more passive (Davies, \& Rogers, 2006; Hunter, 2009). Although negative 
stereotypes openly circulate regarding males who have been abused by adult men, positive stereotypes also exist about the sexual abuse of young men by adult women. It is often falsely believed that boys are lucky to be the sexual conquest of a mature woman, and as such must be sexually desirable and stronger than other young men their age (Alaggia, 2005; Deering, \& Mellor, 2011). While society may view this type of abuse as less damaging, Denov (2004) revealed that victims often felt that they had failed as men as they were abused by the weaker gender. Deering and Mellor (2011) specifically looked at the impact of female perpetrated abuse, and found that this form of CSA led some of the men in their study to demonstrate sexually inappropriate behaviors, often leading them to grow up being very curious and sexually aware, which was not found in the female participants. Denov (2004) similarly interviewed victims of both genders that had been sexually abused during their childhood by women; she found that some male participants expressed having violent sexual fantasies involving women while others, on the contrary, were profoundly uncomfortable with female sexuality. As with other CSA literature, research generally focuses on stereotypical female victim - male abuser dynamics, and is therefore limited in regards to female abusers (Deering \& Mellor, 2011; Denov, 2004).

\section{Disclosure}

Disclosure in childhood. Disclosing CSA is a difficult and complex process that holds several consequences both for the victims, and those around them. While disclosing any type of trauma may be challenging, Bedar-Gilligan, Jaeger, Echiverri-Cohen, and Zoellner (2012) found that disclosing CSA happened even less frequently than with other types of trauma. Disclosure rarely takes place during childhood and several individuals wait years, well in to adulthood to finally disclose the CSA they experienced (Alaggia, 2010; Alaggia, \& Kirshenbaum, 2005; Goodman-Brown, Edelstein, Goodman, Jones, \& Gordon, 2003; McElvaney, Greene, \& Hogan, 
2012; O'Leary, \& Barber, 2008; Paine, \& Hansen, 2002; Ullman, 2003). Children and teenagers who do disclose will generally tell peers more often than they will tell parents or any other adults (Schönbucher, Maier, Mohler-Kuo, Schnyder, \& Landolt, 2012). Alaggia (2005) explained that "not disclosing during victimization may be more common than disclosing, and that significant numbers of children may be left unresponded to and therefore untreated when suffering from negative effects" (p. 454). Deering and Mellor (2011) conducted a qualitative study with 14 adult survivors of CSA; the authors found that the majority of the participants (79\%) did not disclose until later in life, and while the remainder did disclose during childhood only one was believed. Similarly, Jonzon and Lindband (2004) conducted semi-structured interviews with 122 female CSA survivors and found that only $32 \%$ of the participants had disclosed during childhood. The authors noted that despite telling someone about the abuse, 15 victims who disclosed as children continued to be abused afterwards. Parental reaction was found to be critical to the outcome when children disclosed, as Staller, and Nelson-Gardell (2005) noted that "disclosure is not a one-way process. Children receive, process, evaluate, and react to information based on how adults respond to them" (p. 1423).

Unfortunately, delayed disclosure was found to put children at risk of remaining in an abusive situation (Goodman-Brown, et al., 2003). When disclosure is delayed, perpetrators continue to be a risk to victims as well as to other children, as long as they are not apprehended by the authorities (Alaggia, 2010; Alaggia, \& Kirshenbaum, 2005). In addition, by not disclosing the abuse, victims are not made aware of services and cannot receive the proper support and intervention from professionals (Sorsoli, et al., 2008). Similarly, Paine, and Hansen (2002) explained that disclosure of CSA was important as it allowed for both treatment to be possible and an investigation to begin. The authors further noted that without disclosure, the child 
remained at risk and the abuser could continue the behavior, therefore, "a child's ability and willingness to report their victimization plays a critical role in legal and therapeutic intervention" (p. 272). While disclosing can be essential for services to be made available to victims, it also catapults children into an adult world. When children decide to disclose, they enter into a complex world in which the person they disclosed to might have a wide variety of reactions, ranging from disbelief, support, anger, and sadness (Staller, \& Nelson-Gardell, 2005). Ullman (2003) further noted that due to their young age, children who disclosed during their childhood were placed at greater risk due to their limited power and status within the family, making them more vulnerable to family reactions and denial.

When children disclose having been sexually abused, it generally provokes an intense reaction and may lead to various investigation processes (Plummer, \& Eastin, 2007; Rasmusson, 2010). While a medical exam may be performed (Whittier Newton, \& Vandeven, 2010), the exam does not always reveal useful evidence that supports the victims' claims as often, visible trauma cannot be found (Modelli, Galvao, \& Pratesi, 2012). Since medical findings are often inconclusive, children's disclosure becomes essential when attempting to provide evidence against a perpetrator (London, Bruck, Wright, \& Ceci, 2008). It was found that the investigation process combined with the shock of the disclosure placed families in extremely stressful situations (Kuehnle, \& Connell, 2010). Children rarely realize, prior to disclosing, the extent of chaos it can create (Finkel, 2012); the entire process has the potential to provoke full-blown crises due to the high levels of distress it engendered for families (Tavker, \& Hansen, 2011; Paine, \& Hansen, 2002; Ullman, 2003). Disclosure of CSA was also found to lead to several other challenging family situations, ranging from threats from certain members, to complete 
family breakdown (Alaggia, 2004; Staller, \& Nelson-Gardell, 2005); this was especially true when the abuser was a family member (Yancey, \& Hansen, 2010).

Explanations for non-disclosure. While disclosing CSA early seems essential to stopping the abuse, several children are unable to tell anyone for years. Alaggia (2010) examined barriers to disclosure during childhood using an ecological framework. The author distinguished characteristics that acted as barriers to disclosing on the individual, family, community, and at the cultural or societal level. Similarly, Sorsoli (2008) suggested that there were three types of barriers that made disclosing CSA even more challenging than other types of abuse: 1) personal barriers; 2) relational barriers; and 3) sociocultural barriers. While other authors have been able to highlight several challenges that victims have when considering disclosure, it seems that all of them fit in one of the types mentioned by Alaggia or Sorsoli.

Personal or individual barriers encompassed several elements such as victims' being afraid, feeling the abuse was their fault, being threatened, not knowing the behavior was abusive, or feeling ashamed about the abuse (Deering, \& Mellor, 2011; Hunter, 2009). Ullman (2003) similarly noted that the number one reason victims did not disclose was the fear of being blamed for the abuse or the possibility of not being believed. More specifically, Hunter (2011) noted that girls were stopped from disclosing by fear, while boys were stopped by shame; however both genders were impacted by the fear of being blamed. O'Leary and Barber (2008) conducted a quantitative study to examine the gender differences in silencing that existed following CSA disclosure. The authors conducted telephone interviews with 145 men and 151 women and found that males generally took longer than females to disclose and ran an increased risk of being silenced. Schönbucher, et al. (2012) added that some victims either do not want to burden others by disclosing or even deny the abuse in the hopes of suppressing the trauma they experienced. 
Relational or family barriers, such as the relationship the victim has with the abuser also has an important impact on non-disclosure. It has been noted that a close relationship with the abuser, either because the abuser is a family member or a close family friend, tends to stop children from disclosing (Alaggia, 2005; Alaggia, \& Kirshenbaum, 2005; Schönbucher, et al., 2012). London, and al. (2008) explained that children abused by family members take longer to disclose than those abused by strangers since the relationship to the abuser weighs greatly on the child's ability to disclose. By telling others about the abuse, children often fear that they will be betraying a family member or causing problems within their family (Goodman-Brown, et al., 2003; Alaggia, 2005; Schönbucher, et al., 2012).

Finally, sociocultural barriers, which include age and gender as well as cultural norms and taboos regarding sexuality, may also have a negative effect on disclosure and prevent several victims from sharing their experience of abuse (Alaggia, 2004; Alaggia, 2005; Goodman-Brown, et al., 2003). Alaggia and Kirshenbaum (2005) explained that rigid gender roles within a family had the potential to negatively impact children's disclosure, making them less likely to disclose. Additionally, social and community factors can also impact victims' ability to disclose; discrimination, poverty, and disempowerment combined with community alienation perpetuate a climate in which disclosing CSA presents additional challenges for victims (Alaggia, 2005; Alaggia, 2010).

Types of disclosure. Hunter (2011) noted that children have much less control over the disclosure process than adults since "disclosure patterns in childhood are different from those in adulthood in that they are more likely to include behavioral manifestation of distress, such as acting out" (p. 168). While disclosure may differ from one individual to another, and be impacted by variables such as age and gender, specific types of disclosure can nonetheless be identified. 
Finkel (2012) highlighted three different types of disclosure: accidental disclosure; purposeful disclosure, and elicited disclosure. Accidental disclosure referred to accidentally blurting out information about the abuse; while purposeful disclosure related to consciously telling someone; on the other hand, elicited disclosure referred to having someone draw out a victim's abuse experience by questioning them (Finkel, 2012). Alaggia (2004) similarly highlighted various disclosure types; however along with purposeful, accidental and prompted disclosure, she also added behavioral, purposefully withholding, and triggered disclosure. The author noted that behavioral disclosure referred to victims acting out, consciously or not, in the hope that their behavior would alert someone of the abuse; purposefully withholding simply referred to the fact that the victim had not disclosed the abuse despite having the chance to tell; and finally triggered disclosure referred to disclosures that are stimulated by memories of the abuse (Alaggia, 2004).

Disclosure in adulthood. Disclosing CSA much later in life, often in adulthood, is quite frequent for victims (Alaggia, 2004; Hunter, 2011). Evidently, others' beliefs surrounding the abuse still weighs heavily on victims even later in their life; while disclosure may be more frequent in adulthood, it also leads some people to react negatively to victims who withheld their abuse until much later in life (Ahrens, et al., 2010; Jonzon, \& Lindbland, 2004). Dorahy, and Clearwater (2012) similarly explained that the reaction of others is one of the common reasons why adults feared disclosure and why they often isolated themselves from others. Follette, et al., (2009) explained that the feeling of betrayal is increased if after the disclosure the survivor is not believed: "a trusted family member or friend who is unable or unwilling to believe or support the survivor can contribute to the traumagenic dynamics of betrayal"' (p. 232).

The disclosure process is very different from one person to another; some will be comfortable sharing with a professional, while others will prefer telling only specific close friends or family members (Follette, et al., 2009; Sorsoli, et al., 2008; Deering \& Mellor, 2011). 
Jonzon, \& Lindbland (2004) conducted questionnaires and semi-structured interviews with 122 women and found that those who disclosed in childhood were more likely to tell their mother, while those who only disclosed in adulthood had a greater chance of telling a therapist. Perceived levels of support as well as the reactions of the people victims chose to disclose to have an important impact on the disclosure process and the outcomes (Ullman, Foynes, \& Tang, 2010). Professionals can also unfortunately hold preconceived ideas regarding CSA victims as it has been noted that in several cases survivors who first disclosed to a professional where not believed (Dorahy, \& Clearwater, 2012).

Staller and Nelson-Gardell (2005) explained that when survivors meet new people they must make the conscious decision to tell or not to tell: "it means they must continue to make 'first disclosure' decisions with every new relationship. They will have to face continually the decision who to include in the circle of those who know and whom to exclude" (p. 1426). Evidently, disclosure should be seen as an ongoing process between the first time a person discloses and every subsequent time after that, it cannot be seen as a singular event since victims will often disclose to several people at various points in their lives (Ahrens, et al., 2010; Alaggia, 2010; Hunter, 2011). McElvaney, et al. (2012) similarly noted that disclosing CSA should be seen on a continuum: "the process may continue in a "stop-start" fashion throughout the life span" ( $p$. 1169). Staller, and Nelson-Gardell (2005) added that since disclosure it not a linear process it often comes out in incomplete slices throughout a victim's life; sometimes by accident, other times purposefully.

\section{Disclosure Experiences}

Gender differences in disclosure. Much of the literature available regarding CSA disclosure has focused on the retrospective experiences of adult survivors and how they disclosed the abuse. While CSA can affect both males and females, the disclosure process may be 
experienced differently depending on the victim's gender. While this particular thesis seeks to examine specifically the disclosure experiences of men, the following section will also give a brief insight into the experience of women and the gender differences that are salient in this regard. In Canada, Alaggia has significantly contributed to the elaboration and clarification of the topic of disclosure for CSA victims. In her 2004 paper, she examined the elements that promoted positive disclosure in victims of CSA. The author studied a sample of 14 women and 10 men who were recruited through community organizations, two university campuses as well as through word of mouth. She found that feeling safe was important for victims to disclose their abuse. Safety varied from one participant to another and included such elements as creating physical distance with the abuser (e.g. moving to a different city; knowing the abuser had passed away or was in jail, etc). Other participants noted that safety for them was more likely to encompass having a trustworthy person to confide in and talk about the abuse with. The author identified a key difference between genders in the disclosure process; she noted that males tended to disclose less than women due to the greater risk of stigmatization attached to being a male victim of CSA.

In 2005, Alaggia continued her research on disclosure and examined the gender differences that existed in disclosure experiences in a sample of 19 women and 11 men. The author found that while some differences could be found in terms of gender experience, similarities could also be noted. It was further explained that $58 \%$ of the participants only disclosed in adulthood and that several victims, both male and female participants, attempted to disclose in childhood but were unsuccessful. Also relevant for both genders was the fact that those who only disclosed in adulthood tended to do so following a personal breakdown or crisis. Amongst the differences in experience based on gender, Alaggia (2005) noted once again, that concerns regarding homophobic stereotype caused male participants a great deal of anxiety. She 
additionally highlighted the fact that male participants were concerned about being labeled either as a victim or as a potential abuser due to the popular, yet false, notion that male victims of CSA mature into abusers. As for the female participants, they generally felt they were in part responsible for the abuse. The author also noted that women much more than men feared they would be blamed for the abuse.

Hunter (2011) conducted in-depth interviews with 13 female and 9 male CSA survivors and examined the disclosure experience of the participants with the goal of noting the implications for health professionals. Of the 22 participants, 17 disclosed only in adulthood while the others had told someone about the abuse during their childhood. None of the participants felt their disclosure experience was positive or helpful in any way, instead the participants noted that it contributed to further traumatizing them. The trauma was increased by not being believed by those they disclosed to, or by feeling betrayed (usually by their mother) because the abuser remained present in the family. Another article published by Hunter (2009) brought to light the gender differences and similarities in disclosure narratives of this same sample. The author noted that the women in the sample had disclosed earlier than the men, with some women having been motivated to break the silence prior to starting their own family. And while similarities existed between the male and female participants in terms of the impact the CSA had on their lives, the men also struggled with norms around masculinity making it more difficult for them to discuss their abuse history openly.

O'Leary and Barber (2008) conducted a quantitative study of the gender differences in silencing disclosure of CSA. The authors conducted interview questionnaires over the telephone with 145 men and 151 women in order to understand the elements that contributed to them keeping their abuse history secret. As several other authors have noted, it was found that 
disclosure of CSA was often delayed until much later in life, however it was additionally noted that this phenomenon seemed to be even more common in men than in women. In other words, males had an increased chance of being silenced regarding their abuse. The authors noted that social attitudes towards gender seemed to play an important role in the silencing of male victims.

Contrary to the other articles that interviewed adults, Schönbucher, et al (2012) led twopart in-person interviews with 26 adolescents ( 23 girls and 3 boys) to determine the path they followed when disclosing their CSA. The participants were recruited through online media as well as through flyers at their schools; they first completed a standardized questionnaire followed by a second interview segment with open-ended questions. The authors found that $30 \%$ of the participants disclosed the abuse within 24 hours and the remainder of the participants delayed disclosing for varying periods of time. Also contrasting with other articles, Schönbucher, et al (2012) noted that for the majority of the CSA survivors interviewed, the disclosure process was a relatively positive experience as it led them to access the proper services. The authors did not however, make any distinctions based on gender, perhaps due to the small number of male participants.

While gender differences may impact disclosure experience, the gender of the abuser also has the potential of influencing the response survivors get when they talk about the abuse. Deering and Mellor (2011) conducted a qualitative study and recruited 9 men and 5 women who had been sexually abused during their childhood by a woman. The female participants noted that their disclosure of CSA was most often met with disbelief; the fact that a woman had abused them seemed nearly impossible to imagine for several people. On the other hand, when the male participants spoke up about their experience with female perpetrated CSA they were often met with envy and normalization from those around them. Evidently the positive stereotype of the 
older woman seducing the younger boy holds true based on the reactions the participants received.

The male experience with disclosure. As with other literature on CSA, the majority of the studies involving disclosure are based mostly on female accounts and therefore, little is known about how males experience disclosure (Alaggia, 2005). While some articles do address CSA and disclosure, and have an all male sample, they do not necessarily all look at the experience of men with their own disclosure, or when they do, the articles focus on specific elements of the disclosure process. However, due to the limited voice that is given to men in CSA literature, an overview of these articles will be presented in the following section.

Anderson (2011) conducted narrative interviews with 15 male survivors of CSA, and examined how traditional views of men and manliness impacted victims in their disclosure. While the article does not specifically address the experience of disclosing, it does highlight several noteworthy points. Anderson (2011) explained that "men who have experienced sexual abuse are made invisible, hindered from acknowledging their experiences and seeking help" ( $p$. 232). The participants revealed that having been victims of CSA had completely changed their view of themselves as men, often making them feel as if they had failed to be strong enough to control and stop the abusive situation.

Alaggia and Millington (2008) recruited 14 male survivors of CSA through social service agencies and conducted a phenomenological qualitative study that examined their disclosure experience. Of the 14 participants, 5 revealed having repressed some memories of their abuse. The authors identified the key themes that emerged from their interviews and noted that denial of the CSA at some point was frequent in survivors; 10 participants used substance abuse as a tool to forget their history of abuse. Issues regarding sexuality and precocious sexual behavior were 
also common amongst the participants; behaviors manifested themselves in various ways such as getting involved in the sex trade or pornography industry, or demonstrating aggressive or promiscuous sexual behavior. The participants reported having struggled with confusion regarding their role in the abuse, as some felt special for a period of time due to the attention they received from the abuser. The authors noted that issues with anger and aggression were quite prevalent, as 9 participants reported struggling with this. While some participants turned their anger to themselves, others developed violent behaviors towards others. The abuse also led the participants to lose hope in the future and in mankind, several also noted having difficulty maintaining close positive relationships.

Dorahy and Clearwater (2012) conducted a mixed method study using questionnaires and focus groups with 7 male survivors of CSA in order to assess some of the key feelings that emerged from the their experience with CSA and disclosing. The participants were recruited through mental health services. The authors noted that shame and guilt were prevalent amongst the participants. Shame created negative feelings regarding themselves, while guilt led victims to blame themselves, and believe they were partially responsible for the abuse. Ultimately neither shame nor guilt was directed at the abuser; instead, both led the victims to internalize these emotions. The authors additionally noted that participants reported living in constant fear that others around them would learn of the abuse, and tended therefor to isolate themselves to avoid being discovered as victims.

Grossman, and al. (2006) looked at the meaning placed behind the experience of victimization of male CSA survivors. The authors recruited 16 men through therapeutic settings and flyers and conducted 5 hour-long in-depth interviews with them. The authors noted that "one crucial dimension of survivors' recovery is finding a way to "make sense" of what happened to them in the past, and to make some kind of meaning of the place the abuse has in their current 
lives" (p. 434). While making meaning of the abuse is personal to each individual, the authors noted that it may come through psychological or religious frameworks, and often may be a combination of several factors. The majority of the participants were able to make meaning of their abuse through altruism and helping others in need. Several men also attempted to find a meaning behind their abuse by trying to understand the reasons why their abusers acted in such a way; understanding the psychology and the history of their abuser helped men put into perspective the reasons why they had been abused. The authors noted that another common form of meaning creation was through spirituality. While finding meaning through traditional religion was less common, around half the men in the study expressed turning to spirituality and finding comfort and understanding through it.

Sorsoli, and al. (2008) conducted a qualitative study; using grounded theory they conducted two-part, in-depth interviews with 16 male CSA survivors. The participants were recruited through flyers posted in the community and the interviews each lasted between 2 to 3 hours. The goal of the research was to determine the factors that led to barriers in the disclosure experience of the men who participated in the study. The vast majority of the participants solely disclosed in adulthood, only one disclosed as a child. Those who waited till adulthood chose to tell a variety of people they had trusting relationships with such as partners, therapists, friends or family members. While all the participants had disclosed some elements of the abuse at the time of the interviews, 5 had only disclosed very limited information about their abuse. The authors noted that the participants faced different barriers to their disclosure at various times in their life. For instance, personal barriers, linked to cognitive awareness tended to be prevalent in childhood, as were relational barriers due to family dynamics. Sociocultural barriers surfaced more often later in life as they confronted the participants with norms regarding masculinity, victimization and abuse based on social as well as their own cultural norms. 
While most of the research on the topic employed qualitative methodologies, Easton (2013) conducted a quantitative study that addressed disclosure in male victims of CSA. The author recruited participants through various organizations that assisted male survivors and administered anonymous cross-sectional surveys on the Internet to 487 men regarding their history of CSA and their experience with disclosure. Although the majority of the men in the study disclosed in adulthood, those that told as children generally received negative responses. Those who disclosed in adulthood on average delayed telling for more than 20 years. The author further noted that the responses survivors received when they disclosed could greatly impact personal outcomes.

While the effects of CSA are numerous and well researched, the topic of male disclosure in terms of process is still emerging and remains critical to research in order to fully understand the experience of victims during this key step in their recovery. A total of eleven articles that truly addressed the disclosure experience of men and women, or of only men were identified. Of these, six were conducted in North-America (Alaggia, 2010; Alaggia, 2005; Alaggia, 2004; Alaggia, \& Millington, 2008; Easton, 2013; Sorsoli, et al., 2008), three in Europe (Anderson, 2011; O'Leary, \& Barber, 2008; Schönbucher, et al., 2012) and, one each in Australia and New Zealand (Hunter, 2011; Dorahy, \& Clearwater, 2012); none included men from the province of Quebec in their sample. Of the eleven articles that examined the disclosure experience of CSA victims only six solely took in to consideration the perspective of men in regards to their disclosure experience (Anderson, 2011; Alaggia, \& Millington, 2008; Dorahy, \& Clearwater, 2012; Grossman, et al., 2006; Easton, 2013; Sorsoli, et al., 2008).

CSA affects men and women, and yet by focusing greater attention on females, both in the literature and in regards to services (Alaggia, \& Millington, 2008; Diamanduros, et al., 2012; 
Dubé, et al., 2005; Easton, Renner, \& O’Leary, 2013; O’Leary, \& Gould, 2010; Sorsoli, et al., 2008; Ullman, 2003; Valente, 2005), society contributes to telling men that their abuse history is less important. By examining interviews conducted with men regarding their experience with CSA disclosure, a voice will be given to a segment of the sexual abuse population that is all too often pushed aside in the literature to give place to the dominant female perspective. The following thesis will seek to expand on the existing literature on male CSA disclosure in order to answer the subsequent questions: What are the experiences of male CSA survivors in disclosing their abuse? How do these experiences differ or resemble one another? And finally, how do men experience seeking services for CSA?

\section{Methodology}

The following section will describe the methodological approach taken for this study. The goal of this study is to understand the disclosure experience of men who have experienced CSA. For this thesis, the source of data comes from the secondary analysis of telephone interviews conducted with male CSA survivors. More specifically, the next section will address the overall theoretical approach as well as the recruitment strategies employed, a description of the sample, interview strategies and the analysis process.

\section{Study Design}

A combination of two approaches will be employed to examine the research data that informed the conclusions of this thesis. The phenomenological approach and the interpretive description method were selected to offer a complete view of the participants' experience with disclosure, while taking into account the strengths of both approaches.

Phenomenological. The phenomenological approach dates back to the early 1900's and finds its roots in social construction and reflexivity; while often used in the fields of psychology 
and nursing, this approach marries itself well to most social science fields (Padgett, 2008). The phenomenological approach is used in qualitative research and focuses mainly on how a certain event is experienced by individuals. "In phenomenology, reality is comprehended through embodied experience [and] capture[s] the meaning of common features, or essences, of an experience or event" (Starks, \& Brown Trinidad, 2007, p. 1374). Fater and Mullaney (2000) added that this approach truly seeks to show the meaning people associate with an incident or experience. Starks, and Brown Trinidad (2007) further explained that the phenomenological approach delves deeper and more profoundly in the lived experience of people in hopes of uncovering knowledge true to that person. The authors added that the 'truth' that a person feels regarding an event is subjective as it focuses on their own experience, their own perception, and is therefore specific to what they have lived through. Padgett (2008) noted that when using this methodology "analyses of interview data are conducted to find the 'essence' or common themes" in the experience of the individuals (p.35). In the case of this specific thesis, the use of the phenomenological methodology will helps us understand the experience of men who disclosed their CSA histories, by uncovering the common themes that exist amongst the participants. While the phenomenological approach seems to be well suited to illustrate the core experiences of the participants in this thesis, three issues arise preventing this study from being truly phenomenologically based. Indeed, the methods required to obtain such in depth information can only truly be put in place with careful planning during the recruitment phase. First off, Creswell (2007) explained that in order to achieve the full depth of the experience, multiple interviews with each participant are required. However, in the course of this thesis, previously collected data will be used to conduct a secondary analysis of existing interview transcripts to answer the proposed research questions. It will therefore not be possible to stay completely true to the phenomenological approach as the participants were only interviewed once 
and will not be contacted for further interviews. A second limiting factor relates to sample size traditional phenomenological techniques call for samples ranging between 6 and 10 participants (Padgett, 2008), less than the sample of 17 participants that will be examined in this thesis. Finally, Thorne (2000) explained that a true phenomenological approach generally "avoid[s] cross comparison and instead orients the researcher towards the depth and details that can be appreciated only through an exhaustive, systematic, and reflective study of experiences as they are lived" (p. 69). While the essence of the disclosure experience of the participants will be key in the analysis of the findings, some cross comparison between participants will also take place, preventing the study from being solely phenomenological.

Interpretive description. In order to bridge the limitations of the phenomenological approach in the context of this thesis, a second approach, interpretive description, will be used in conjunction. Deeply rooted in qualitative research, interpretive description originated in the late 1990 's in the field of nursing studies as a pragmatic solution to maintain theoretical integrity as well as utility of knowledge; in other words interpretive description is an applied process that seeks to ensure that knowledge obtained through the course of research can be easily transferred to practice settings (Thorne, 2008; Thorne, Reimer Kirkman, \& O'Flynn-Magee, 2004). StGeorge (2010) noted that interpretive description is a method clearly aimed at clinicians and practice oriented researchers, and while this method was specifically created to fit in with the needs of the field of nursing, the author maintained that the method could easily have merit for practitioners working in a wide variety of domains. By turning research findings into usable information for practice settings, interpretive description ensures that there is a useful rationale behind research topics and that findings are not only used to advance knowledge but also to lead to better practice in clinical settings (Hunt, 2009; Thorne, 2008; St-George, 2010). In the realm of interpretive description, data collections techniques as well as data analysis are free to vary 
according to the project, which in turn allows researchers more flexibility as it avoids dictating sample size, interview method, or analysis tools (Thorne, et al., 2004).

Interpretive description is a flexible method that seeks real life relevance, and encourages researchers to utilize their clinical experience in order to form the research topic, with the main goal of organizing "data analysis towards the development of findings that will assist health care professionals in their practice" (Hunt, 2009, p. 1289). While the thesis in question will address suggestions for practice, the main goal of the research will also be to give a voice to male survivors of CSA in regards to their experience with disclosure. Although the interpretive description approach breaths promise, its newness has some limitations. Amongst the limitations of the interpretive description methodology, Hunt (2009) highlighted that since the approach is still relatively new there is a limited amount of researchers that have used this method thus far, leaving few examples to follow besides the main texts available on the topic. It seems therefore relevant to marry the phenomenological approach, which is an older traditional qualitative methodology with interpretive description in order to provide a deeper understanding of the participants' experiences and find the best alternative possible, given the available data, to give them a voice.

\section{Data Collection}

The use of telephone interviews in research. Telephone interviews have generally been employed in large-scale quantitative researches, and are felt by some to be better suited for the administration of surveys (Musselwhite, Cuff, Mcgregor, \& King, 2007; Sturges, \& Hanrahan, 2004; Novick, 2008). However, Carr and Worth (2001) conducted a literature review regarding the use of telephone interviews in research and noted that although somewhat less common, this communication method was also used in smaller qualitative studies. The authors further 
explained that the use of telephones as a research tool coincided with changes brought on in recent decades by technological advances, as well as the social acceptance, and prevalence of telephones in most homes. Telephone interviews have additionally been found to be useful in helping researchers access hard to reach participants who are either reluctant to partake in faceto-face interviews or difficult to reach due to their geographical distance (Holt, 2010; Sturges, \& Hanrahan, 2004).

While studies that compare the quality of telephone interviews with in-person interviews are rather limited, they appear to conclude that the quality of the data obtained is at least comparable (Carr, \& Worth, 2001). Sturges and Hanrahan (2004) conducted a research project for which they interviewed correctional officers and visitors at a county jail. While the original study design called for in-person interviews, the authors were obliged to conduct half the interviews over the phone due to various scheduling conflicts. The authors found that few differences could be found between the in-person and telephone interviews. The authors also noted that the method of interview did not appear to influence the responses the participants gave as individual questions demonstrated similar qualities and depth, independently of the way in which the interview was conducted. Following a review of literature, Novick (2008) similarly concluded that "there is relatively little formal evidence to be found regarding [the] merits and shortcomings of [telephone interviews] vis-à-vis face-to-face interviews [and] given the lack of evidence, it is unwarranted to favour any particular interview mode for qualitative interviews" ( $p$. 394).

Although much debate continues to circulate surrounding the use of telephone interviews, several advantages to this method have been found. Norvick (2008) explained that by using telephone interviews to collect data, researchers allow for more flexibility and control by the participant. The author maintained that this method allowed respondents to choose a location, 
usually their home, as well as a time that was most convenient to them; telephone interviews also offered easy rescheduling possibilities when needed. Conducting interviews by telephone was also found to offer a greater anonymity to participants, which could potentially allow them to speak more openly to the interviewer about their experience without fear of judgment (Musselwhite, et al., 2007; Carr, \& Worth, 2001). Additionally, using the telephone to conduct interviews has been found to be both time and cost effective, limiting unnecessary traveling and hence creating a more efficient means of obtaining data, all the while allowing for the interviewer to remain safe by avoiding to meet participants at the their home (Musselwhite, et al., 2007; Carr, \& Worth, 2001).

The telephone may be a useful tool to conduct interviews however this method also contains certain disadvantages. The absence of non-verbal and visual cues such as eye contact and nodding to probe for information or to allow time for the participant to reflect were clear drawbacks of the telephone interview (Norvick, 2008; Holt, 2010). Holts (2010) conducted telephone interviews in the course of her research and concluded the process by asking the participants to gage their level of appreciation regarding the use of telephone as an interview tool. While the participants responded that they found the lack of visual contact with the interviewer challenging, especially when long pauses took place, they also reportedly enjoyed the interview process and compared it to a comfortable telephone conversation.

Recruitment. Recruitment took place from May 2011 to July 2012; male and female participants were recruited in four large Canadian cities: Montreal, Ottawa, Toronto and Calgary. The participants were recruited through either community organizations that offered support services to sexual abuse victims or mental health organizations that also helped CSA victims. Inclusion criteria for participants were:

1) Being over the age of 19 ; 


\section{2) A self-reported victim of CSA;}

3) Have recently received or be currently receiving services for their abuse history in one of the organizations in which the recruitment process took place.

Research assistants put up posters describing the study in the waiting rooms and bathrooms of the organizations in which the recruitment took place. Workers in the community organizations played a critical role in the recruitment process as they handed-out pamphlets outlining the study to the potential participants when they fit the recruitment criteria (see Appendix A for a copy of the poster and pamphlet used for the recruitment). Those who were interested in the study were invited to call the number that appeared on the poster and pamphlet to discuss their potential participation; when they called, they were asked to leave their name, telephone number, as well as the best time to reach them. The calls were then returned by one of the research assistants who was able to answer any questions the participants had since she coordinated the project and acted as lead interviewer. Following the participant's expression of interest in the project, a consent form was mailed to an address of their choice. The consent form was then read over with them on the telephone (see Appendix B for a copy of the consent form). The participants' consent was digitally recorded, they were then asked to sign and mail a copy of the consent form to the research team in a self-addressed envelope that was provided to them. The digital recordings of the consent, as well as the signed consent remain stored in a locked filling cabinet in the research office at McGill University. A \$20 gift card to a popular coffee shop was given to all the participants to thank them for their time; the gift card was mailed to them using the address they had provided.

Ethics. The study was reviewed and approved by the McGill Research Ethics Board (see Appendices $\mathrm{C}$ for a copy of the initial ethics certificate as well as the current one for secondary use of data). Certain measures were put in place to protect participants' emotional wellbeing. 
Only individuals who had recently received or were currently receiving services for their abuse history were eligible to participate in the study as it ensured that participants would be able to contact their worker and receive prompt psychological help if the interview brought up some negative emotions. The interviewers remained attentive throughout the interviews to any possible distress from the participants and encouraged them to take brakes when needed; and were able to provide the participants with sexual abuse resources in their region, if need be. Additionally, the interviewers were trained in crisis intervention and suicide intervention, in the unlikely case in which the interviews were to necessitate it. The interviewers conducted a follow-up telephone call to each participant approximately one week after the interview took place to ensure that the process had not left them emotionally troubled and to answer any additional questions they could have.

Methods and data collection instruments. Semi-structured interviews were conducted with the participants over the telephone. The interviews ranged approximately from 45 to 90 minutes in length, and were digitally recorded. Three female interviewers, each with a Masters' in Social Work conducted the interviews; both Francophone and Anglophone interviewers were available to ensure that the participants spoke with a person with whom they could easily communicate.

The questionnaire focused mainly on the disclosure process, as well as barriers and facilitators to the disclosure process. The questionnaire included eight open-ended questions that created several opportunities to further explore the participants' experiences (see Appendix D for a copy of the interview questionnaire). The first question was: "what prompted you to seek help about the abuse at this time and with this organization?" depending on the participants response, the interviewers would then go on to ask a question such as: "how positive or negative was this experience for you?" and then would introduce the topic of disclosure with a question such as: 
"was it the first time you disclosed the abuse?" Prior to commencing the interview the participants were reminded that they were free to refuse to answer any specific questions with which they were uncomfortable, without giving further explanation. Finally, demographic information was collected at the end of the interview in order to give a general idea of the profile of the participants.

\section{Sampling}

The sampling strategy was purposeful and did not try to be representative of the general population; instead it was aimed at recruiting male and female participants that matched the research criteria. Initially, it was hoped that twenty (20) participants would be recruited each in Quebec, Ontario, and Alberta, in order to give an equal representation of each province. While both male and female participants were recruited, there were no specific numbers expected in regards to their gender, although it was believed that more women would be recruited since a number of the recruitment sites offered services only to female victims. Recruitment was very fruitful in Quebec, potentially due to the high level of organization of sexual abuse services that exist. In the two other provinces, recruitment mostly took place in community organizations and family service centers that offer mental health services and that had some CSA clientele, which diluted the number of CSA survivors and therefore of potential participants; some specialized CSA organization were also recruited at. No participants were recruited in Alberta and recruitment in Ontario proved to be much more difficult than in Quebec. The challenges in recruitment could have potentially been caused by the variation in the type of organization and could also have been influenced by the researchers' affiliation with McGill University (located in Quebec). Recruitment was continued in Quebec despite having reached the expected numbers for the province since the number of participants recruited for the other provinces had been below expectations; and was stopped when interest in the project diminished. 
In total 69 male and female participants were recruited from three large Canadian Cities: Montreal, Ottawa, and Toronto, with none recruited in Calgary. Of the original sample of 69, one participant was removed from the sample by the researcher due to the fact that his interview did not contain information relative to his disclosure experience and was tainted by mental health issues; leaving the final sample of 68 participants.

The male participants totaled 17 ( $25 \%$ of the entire sample), and lived in the greater Montreal or greater Toronto areas; no male participants were recruited in Ottawa. Eleven (11) male participants were Francophone while six (6) were Anglophone. Their age ranged from 19 to 67, with the average of 47 years old and a median of 48. Eight (8) participants held at least one university degree (either at the Bachelor or the Master level); four (4) had a college education; and five (5) participants either had a high school education, or had stopped their schooling during high school. All, but one, of the participants agreed to be digitally recorded during their interview. The interviewer took careful notes while interviewing the individual who refused to be recorded, and although verbatim data was not available, these notes were used during the data analysis process.

The men in the sample were sexually abused by a wide range of individuals; four (4) were abused by women, while thirteen (13) were abused by men. Several men were sexually abused by close relative: two (2) were sexually abused by a parent (one was abused by his mother and the other by his father); two (2) were sexually abused by a sibling (one was abused by his sister, and the other by his older brother); and three (3) were sexually abused by a family member (other than a parent or sibling). Three (3) of the men were sexually abused by a neighbour; two (2) were sexually abused by a teenager; six (6) were sexually abused by a trusted adult (e.g. a family friend, or an older sibling's spouse); and only one (1) was sexually abused by a stranger. Three (3) men were sexually abused by more than one person; for two participants the CSA abuse was 
committed by two different men; while for the third the abuse was committed by both male and female abusers, and took place at different times. One (1) participant did not identify who his abuser was (see Appendix E for table describing the sample).

Four (4) participants mentioned that there was some level of dysfunction in their family growing up (e.g. severe mental health issues, or alcohol and drug abuse). Four (4) participants were also victims of other forms of child abuse growing up; the abuse they endured was not necessarily perpetrated by the same individual that committed the CSA, and ranged from verbal and psychological abuse, to severe physical abuse.

\section{Data Analysis}

Literature. Using Saladaña's (2013) manual on coding as a guide, the codes were initially selected using a combination of descriptive and emotion coding. While descriptive coding generally seeks to identify the concrete elements that surface in interviews, emotion coding attempts to identify the experience, as well as the participants' emotions. Saladaña maintained that coding methods needed to match the needs of a project and could be combined, creating a customized hybrid method. The author nodded that both coding methods worked well for most qualitative research; descriptive coding was found to be ideal for new researchers beginning in the field, while emotion coding was particularly well suited for projects "that explore[d] intrapersonal and interpersonal participant experiences and actions" (p. 105). As Saladaña explained, "rarely will anyone get the coding right the first time" (Saladaña, 2013, p. $10)$; it is therefore expected that this process will need to be repeated and transformed with time. Thorne, et al. (2004) similarly suggested that the process of coding should take time, the authors noted that the analyst should remain sceptical of elements that become immediately apparent or that rest on earlier conceptualization; rather the authors maintained that the data analysis period 
should "search out alternative linkage, exceptional instances, and contrary cases as a mechanism for broadening rather than narrowing conceptual linkages" (p. 5).

Saladaña (2013) recommended that "first time [...] studies, code on hard-copy printouts first, not via a computer monitor" (p. 26). The categorizing of codes is simply the organization of similar codes into groups based on emerging patterns (Saladaña, 2013). While the process of extracting themes from the data in the context of qualitative research is sometimes rushed, Saladaña warned that themes should not be seen as codes, and should not be easily 'picked out' from the data; rather, themes are an outcome of the coding and categorizing process, one that requires a great deal of reflection and analytic processing. While "there are many qualitative data analysis computer programs available on the market today, these are essentially aids to sorting and organizing sets of qualitative data, and none are capable of the intellectual and conceptualizing processes required to transform data into meaningful findings" (Thorne, 2000, p. $68)$.

Rigour. Padgett (2008) described rigour as being an essential part of the qualitative researchers process to ensure that data is valid. In order to reach rigour and trustworthiness, studies need to ensure that the researchers interpretation of the data corresponds to the participants' views; that the study can be reproduced by others; that the process has been well documented; and finally that results are representative of the data (Padgett, 2008). Establishing trustworthiness for this thesis was completed primarily through peer debriefing and support, as well as through the completion of an audit trail. The masters' candidate's supervisor as well as the original project coordinator played an important role in the debriefing process as well as the establishment of consensus. Attempts were also made to keep track of feelings and impressions about individual interviews, in the form of an audit trail, in order to identify areas of sensitivity that might be more susceptible to influence the coding process. Saladaña (2013) explained that 
each researcher's own analytic approach impacts coding, as personal values and beliefs enter into the choice of codes and the methods in which segments of text are identified as belonging to a certain code; it is therefore preferable to use analytic memos and write down these impressions as the coding progresses.

Coding, categorizing and themes. The 17 interviews were initially digitally recorded and then transcribed verbatim and placed into Word files. All transcripts were then read by the primary analyst (masters' candidate); on the basis of this initial reading a preliminary coding structure began, each interview was subsequently re-read and coded according to the codes that had been established. During this period new codes were added and decisions were made to merge or remove initial codes from coding scheme. The interviews were manually coded systematically line by line and sorted into Word files. The transcripts were initially inductively coded by the primary analyst into over 70 codes; and placed in Word files. The codes were eventually broken down in a little over 20 categories, which were later placed into several subthemes that emerged into four overarching main themes. The masters' candidate's as well as the project coordinator acted as secondary analysts and were consulted to critically discuss the coding decisions. An added challenge to the coding process for this project was that 6 interviews were in English and 11 were in French. Since the main language of the research is English, the French interviews were coded using English codes and the sections of text identified by the codes were then translated in to English staying as true as possible to the participants' initial words.

\section{Results}

In the following section the main themes that emerged from the data analysis will be presented. Four overarching themes were identified, each with several sub-themes. The first theme addressed the impact of the abuse on the men, specifically looking at the externalized and 
internalized behavior, and the challenges the men faced in their interpersonal relationships. The second theme focused on the participants' disclosure trajectory, and specifically addressed the experience of disclosing for the first time, as well as the delays and hesitations surrounding talking about the abuse, and the various elements that contributed to motivate or delay the participants' disclosure. The third theme looked specifically at the positive and negative experiences the participants had with disclosure, including the level of support they received, as well as the impact of not disclosing. Finally, the fourth theme addressed the participants' experience of seeking CSA services, by focusing on the elements that led them to get help, their involvement in the various services as well as the challenges obtaining services could present for male victims of CSA.

\section{Impact of the Abuse on Various Spheres the Men's Lives}

Externalized behavior. The participants' history of CSA was found to have a grave impact on different aspects of their lives and in some cases the impact was demonstrated through externalized behaviors. The participants described using various coping mechanisms to deal with their history of CSA such as externalizing their anger and drowning out the abuse with substance use.

Presence of anger. A number of participants demonstrated some form of aggressive behaviors at various points in their lives. Three (3) participants expressed feeling extremely angry about their abuse, Sam* for instance explained that "what makes me absolutely angry, (is that) somebody took my potential, my birthright". Richard on the other hand, noted that as a child he had struggled with anger, never really understanding the reason behind his feelings: "I was an angry kid that didn't know why". The idea that someone had taken something from them led

\footnotetext{
* All the men's names have been changed
} 
some men to demonstrate aggressive or even violent behaviors. In the case of one (1) other participant, the anger boiled up and led him to be abusive in his past romantic relationships. Four (4) participants also described explicit fantasies and desires to harm or kill the person who had abused them. Serge's anger and hate towards his abuser was palpable, suggesting he might even have been a danger had the abuser not passed away: "I'd kill him with my bare hands if he was still alive - I hated his guts"** . Mario also expressed wanting, at a certain level, to physically harm his abuser: "If I were to see him (the abuser) today, well, I would really let him have it, but if I was caught, I would be the one going to prison..."**. Despite his anger, Mario's rational thinking allowed him to understand that he could potentially have legal problems if he were to actually attempt to harm the person who had sexually abused him as a child.

Drowning out the abuse. Several of the men interviewed mentioned having struggled with substance use at various times. While only two (2) participants reported having abused drugs, a total of seven (7) men revealed having had some difficulty with alcohol consumption at some point in their lives. Martin explained that he used alcohol as a way of exteriorizing his abuse:

I was also partying like mad because I was always looking for a way to just kind of let it out, like to get this stuff out (the abuse), and the way I did it was through, I mean, just excessive drinking.

Another way the participants were found to 'drown out' the abuse was through rebellious behaviors during their teenage years. Three (3) participants described having acted out a fair deal growing up. Behaviors ranged from dangerous and reckless driving to total disregard for authority figures.

\footnotetext{
** Quote translated from French to English
} 
Internalized behaviors. An even greater number of internalized coping behaviors were identified amongst the participants. The internalized coping mechanisms identified included social adaptation issues; anxiety related issues; mental health problems; and finally emotional struggles.

Social adaptation issues. Issues related to social adaptation were evident in the experiences of some of the men interviewed. Four (4) participants revealed being quite concerned about how they were seen by others, which created self-esteem issues for them. In the case of two (2) participants, the fear of being marginalized by others led them to isolate themselves from friends and family. While emotionally painful, keeping others at bay seemed to protect the men from their fear of being judged. Ted further explained that the energy required to deal with the trauma of his abuse was often so great that he was unable to maintain other relationships:

When you become aware of the abuse, well, it's like, that soaks up so much of your energy that we cut ourselves off from others - we keep our distance - actually, we need to keep our distance (...) so we isolate ourselves. Now I understand that isolation is a kind of defense mechanism - it's $\mathrm{OK}^{* *}$.

One (1) participant also revealed having struggled with homelessness for a period of time. Social adaptation issues contributed to the creation of barriers between the men in the sample and those close to them.

Anxiety related issues. Anxiety related problems were fairly common amongst the men that were interviewed. Five (5) participants expressed having struggled with anxiety throughout their lives; Martin's anxiety was hard for him to control when he was younger and often resulted in physical manifestations: "when I was 18, I was pretty, I was kind of having problems with panic attacks, so I went to see (a professional for help)". Four (4) men also noted that they believed they suffered from PTSD. Difficulty sleeping was additionally found in three (3) other

\footnotetext{
** Quote translated from French to English
} 
men and ranged from occasional nightmares to full-blown night terrors; almost 45 years after being abused by his older brother, Sam expressed that he was still struggling with going to sleep: “because I was sexually assaulted while I was asleep in my bed, I'm a nervous sleeper (...) I can't sleep". While anxiety manifested itself differently from one man to another, it not only impacted daily living but also affected other aspects of their lives.

Other mental health problems. Several participants expressed having struggled with various forms of mental health issues at one point during their lives; some had received official diagnoses while others simply described their symptoms. In total, eight (8) men had experienced depression. As Richard expressed, the longstanding effects of depression often robbed the men of positive life experiences: "I missed out on so much with all the severe depression (...) that I've been through". Two (2) participants had also received diagnoses and treatment for other mental health issues (bipolar and borderline disorder). Suicidality was a common issue among participants, as Sam explained, the abuse he suffered had, at times, removed his will to live: "I couldn't care less if I lived or died (...) I'd lost my drive for life". While two (2) men admitted having attempted suicide, five (5) mentioned having thought about dying or taking their own lives to ease their suffering at some point. For Ted, who had attempted suicide in his late teens, the abuse itself was a form of death: "you know, when those abuses happened, it was like part of me was killed, part of me died... I realized that basically, huh, when you are abused by an adult, huh, that adult is killing part of us..."**. At their worst, the mental health challenges the men faced had the potential to take their life, however, even those who did not attempt suicide were profoundly distressed by the symptoms they faced.

Emotional struggles. The men in the sample revealed having struggled with several difficult emotions in link with the CSA they had experienced. A total of eight (8) participants

\footnotetext{
** Quote translated from French to English
} 
expressed feeling deeply ashamed of having been abused, as Jean-Marc simply expressed "I was ashamed of myself ${ }^{, * *}$. His feelings were echoed by Serge who similarly explained that shame inhabited him: "when you have been sexually abused your life is filled with shame and guilt"** $^{\text {** }}$ Shame led the men to feel humiliated, and even dishonoured by the abuse they suffered, three (3) participants also noted that their history of CSA led them to feel a great deal of embarrassment. Jacob felt both shame and embarrassment, and was very concerned about how he would be seen by others: "it was very hard, it wasn't easy um... like I said, I was very ashamed, I was embarrassed"; Jacob's link to his cultural heritage increased his embarrassment as he felt CSA did not happen in 'good' Jewish homes. Guilt was another common emotion amongst the participants; indeed four (4) men expressed feeling some level of guilt or responsibility regarding the abuse. James felt a great deal of guilt as he felt he should have been able to avoid the abusive situation since his parents had often warned him about sexual predators: "I should have known better, like I mean, they told me to lookout (for abusers) and you know, look at the mess I got myself into". The feelings of guilt expressed by James and the other men were often characterized by the sense that the abuse was their fault in some way.

Stunted interpersonal skills. Problems with various types of personal relationships were frequent for the men interviewed and caused them a great deal of grief. It seems obvious that the history of CSA of the participants appeared to have contributed to stunting the development of fulfilling relationships. While issues surrounding romantic and sexual relationships seemed to be the most salient, challenges in the parental and professional spheres were also evident amongst the sample.

** Quote translated from French to English 
Issues in romantic relationships. An overwhelming majority of the men in this study reported having struggled with various aspects of their love life. In total, eleven (11) participants expressed having difficulties sustaining romantic relationships. James explained that being in a romantic relationship just did not feel right: "trying to have a relationship, a normal relationship, um it felt very weird". Sam on the other hand, expressed a more fatalistic view of his relationships: “all (my) relationships failed because they’re all... they're all a disease from my disease, which is my, my, my sexual abuse". Both men articulated a certain level of discomfort with romantic relationships and felt their abuse paralyzed them from fulfilling their romantic potential. Sexual difficulties were also a challenge for five (5) men in the study. While one (1) man reported frequently using the services of massage parlors and escorts, most of the other men reported having difficulty with sexual intimacy and arousal. Mario explained that his romantic relationships suffered due to his sexual difficulties: "I had a kind of sexual blockage - things just didn't work with my girlfriends" ${ }^{* *}$. Ted similarly described how his issues surrounding sexuality were a constant constraint to forming a romantic relationship with a woman:

I have a lot of problems with sex, problems of impotence, fear of intimacy, whew, all of that. It has bothered me all my life and, you know, it still affects me, yeah, I, basically my relationships with women are awful, if you know what I mean ${ }^{* *}$.

Sexual challenges caused the men a great deal of grief as it all too often prevented them from forming fulfilling positive relationships.

Issues surrounding parenting. Problems related to parenting were less frequent as only one (1) man revealed having a strained relationship with his child. However, fears related to parenting skills were evident in the dialogue of two (2) men. As Martin explained, the experience of being victimized as a child left him with doubts regarding his own parenting ability:

\footnotetext{
** Quote translated from French to English
} 
My partner wanted a child and I was, like, literally thinking that having a child was like putting a gun to my head, and so you know, I was so scared of, of being in that position, of being with a kid, (...) I have no sexual feeling towards kids, I've never been violent towards kids but (...) I don't know what, I'm like under huge pressure.

Issues in the workplace. Challenging relationships were also present, for some participants, in their professional life. Two (2) men expressed having difficulty maintaining positive relationships in the work place, either with their bosses or their colleagues. Robert explained that remaining employed had been a challenge for him due to the interactions he had with the other workers at his job: "I was having difficulty um... uh interacting with coworkers and supervisors um at the last job I had (and) I walked off the job”. While not necessarily related to the interpersonal skills of the men, three (3) participants also noted that they struggled financially.

\section{Disclosure Trajectory}

The disclosure process was experienced differently by each participant, however certain similarities surfaced. Trajectory patterns, while different from one participant to another, generally indicated that disclosure happened during adulthood, and was shared with a variety of individuals. Elements surrounding flashbacks, denial and repressed memories of the CSA were also evident in the journey of certain participants.

Disclosing for the first time. While the disclosure process for all the participants' interviewed included more than one person, their initial disclosure was often a very significant one and generally spoke to their life stage. Five (5) men disclosed for the first time to a professional; generally this was either in individual therapy or in the context of a men's survivor group. James for instance disclosed for the first time during one-on-one sessions with his counsellor; he explained that: "it was very very basic, I was quite nervous and embarrassed (...) the counsellor definitely was uh, helpful". Richard also disclosed to a professional for the first 
time, however, unlike the other men, he disclosed after being pressured by a police officer who was trying to complete a case regarding CSA in a reform school he attended as a teenager. Five (5) participants disclosed for the first time to a member of their biological family; of these men, three (3) had disclosed during their childhood. For three (3) other participants, their first disclosure was to their spouse or partner, while three (3) other men first told a close friend. Christophe disclosed to several people; he explained however that disclosing initially to his friend is what helped him feel comfortable disclosing to others:

I talked about it with a friend, a really good friend, about what happened and gradually, I was able to tell her more and more - I realized that I also needed to talk about it with my family, and the more I spoke about the experience, the more liberated I felt as well ${ }^{* *}$.

Waiting to tell. All the men in the study waited to disclose their CSA, however the amount of time it took them to tell varied a great deal between the participants. Only four (4) men were able to disclose their abuse during their childhood. Philip waited one year before telling his mother that her male friend who regularly watched over him and his older brother had abused him; Philip feared repercussions from the abuser but also expressed some confusion that he attributed to his young age:

It didn't seem to matter who I spoke to, whew, it was going to be my fault - the (abuser) was going to get mad at me and, you know, at that age you don't really know what is right and what is wrong ${ }^{* *}$.

Of the four (4) men who disclosed during their childhood, two (2) had been threatened with violence by the abuser if they disclosed. Two (2) other participants made indirect attempts to disclose but were not taken seriously. Serge for example made several explicit comments to his father regarding the man who abused him; his father ignored the disclosure attempts and instead continued to favor the abuser, as he was a well-respected member of their community. Serge

** Quote translated from French to English 
explained that his failed attempts led him to feel unprotected by the adults around him: "at that point, since I wasn't being protected, I didn't trust the adult world to protect me" ** . Had the parents of these boys been more attentive to their attempts to disclose, they to, might have told earlier.

In total thirteen (13) men expressed waiting until adulthood to disclose their history of CSA for the first time. Sam described the process as having been extremely difficult: "it was excruciatingly hard even to say it... I did it on the telephone (it) took me a long time even to say it, to push back tears". Christophe disclosed as a young adult and expressed having felt a need to share his abuse history with the people around him: "I just sort of felt a need to tell, not to tell everyone, but I had a need to tell the people concerned by it, my friends, family members, the abuser or the police, even" ".* James also disclosed in early adulthood, and while he had been repeatedly questioned by his mother who suspected the abuse during his adolescence, he was so concerned he would disappoint her that he never felt able to tell until several years later: "I couldn't tell anybody because I felt like people would be disappointed in me". Similarly, Jacob waited almost twenty years before disclosing his abuse, the shame he felt during his childhood prevented him from telling: "I would never talk to, uh, about it with anyone, I was, I was too much ashamed". For other participants, such as Sam, it was not the shame, or the fear of how others would react that stopped them from telling but simply the feeling there was nobody to listen to them. Sam and his younger sister were both sexually abused by their older brother; after his sister disclosed to their parents and the abuse continued, Sam felt there was no one he could turn to: "I had nobody to tell (in childhood)". Waiting to tell was common for the men in the sample, some even waited decades before finally sharing their secret.

\footnotetext{
** Quote translated from French to English
} 
Stereotypes contributing to delayed disclosure. Disclosing their abuse history was

often made more challenging for the participants due to the numerous stereotypes and taboos that surround male CSA. Specifically, six (6) men spoke about the taboo that surrounded male sexual abuse and the difficulties linked to even being recognized as a victim. Four (4) participants expressed that being male and a victim of sexual abuse did not match with the masculine ideal and that in a homophobic culture they could potentially be labeled as less manly or as homosexual if they disclosed their abuse. Sam explained how gender norms were formed in childhood for him: “in my day (men were) taught to be tough... don't show emotions (...) that kind of thing, right, that's only for weaklings, and, and fairies or whatever". Sam felt that by telling others about his abuse he was labelling himself as less of man. Another label that was feared by two (2) men in the sample was that of potential child abuser; this was a real fear for Sam: "if they knew I was sexually abused, they may think that I will sexually abuse their children". Common stereotypes surrounding male CSA led some of the participants to fear what others would think and created important deterrents to their disclosure. Additionally, two (2) men who had been abused by women also noted how the taboo of male CSA was only increased when the abuser was female. Simon noted that for himself, and for society in general, there is a belief that abusers are solely male:

I was abused by a woman, I wasn't abused by a man (but) for me sexual abuse is when a man abuses... a little boy or a little girl, and the abuse is clear when that happens (not like when a woman is the abuser) ${ }^{* *}$.

Simon's notion that the sexual abuser could not be female kept him in denial, and contributed to him waiting 20 years before telling anybody about the abuse. Jeremy who was abused over a period of 4 years by his teenage girlfriend's mother similarly highlighted that: "we have this image of the guy who, who, who is an abuser, but the image of a woman who is an abuser, umm

\footnotetext{
** Quote translated from French to English
} 
that doesn't exist. A woman abused me, and it's like... it wasn't normal"**; he further explained how he was often met with ridicule or envy when he disclosed his abuse due to the gender of his abuser: "you can't talk to anyone that a woman is abusing you, I mean if I did talk about it, it was like 'right on!' ... that was the reaction I got from people" **. Fear of being further ridiculed prevented Jeremy from disclosing and led him be extremely cautious when he did tell.

Trying to forget. In total, nine (9) participants described various ways in which they had repressed some elements of their abuse history. Some men explicitly mentioned having been in denial of the abuse and purposefully trying to forget their experiences, Christophe linked his profound denial with his inability to disclose earlier: "I was in complete denial and didn't talk about it at all and when I did finally talk about it I was disconnected"**. Other participants described having struggled with unconsciously repressed memories; James described how flashbacks of the abuse could be easily triggered and surfaced years later: "I had even had repressed memories, I had just um a couple weeks ago (I) was, was reading a book, like my counselor gave me and uh (it) triggered some flashbacks of uh other abuse". Richard similarly struggled with repressed memories for years and explained that the effects could be felt physically as well: “(my abuse) was completely blacked out from (age) 6, to whatever... 47 (...) I always knew there was something wrong but I couldn't pinpoint it (and) I felt physically faint after some of the flashbacks I was having”. Philip who also struggled with lost memories, compared his flashbacks to video sequences of the abuse that replayed in his head: "(I have) flashbacks, but not really flashbacks, it's more like little pieces of, little video sequences or videos that popped into my, well, my head"** Whether consciously or not, memories of CSA

\footnotetext{
** Quote translated from French to English
} 
appeared to be so traumatic for the men that they forgot, in some cases for several decades, certain elements of the abuse.

\section{Breaking the isolation as a motivator to disclosure}

Knowing other victims of CSA helped men feel less alone in their experience and often encouraged disclosure. Eight (8) participants spoke about feeling less isolated or more comfortable disclosing knowing that others had experienced similar abuse. Several men expressed personally knowing (outside of therapeutic group settings) at least one, and in some cases several individuals who had also been a victim of CSA at some point in their lives. Six (6) men spoke about other family members having been sexually abused; Philip spoke about learning his mother's abuse history, and finally feeling that she could truly understand him:

I had decided to keep quiet until my mother came and sat with me and told me 'it also happened to me' (...) it hadn't just happened to me (...) then I knew that since she knew, she understood what I had experienced, I could tell her my story ${ }^{* *}$.

Similarly four (4) men explained that their spouses or partners had also experienced some form of CSA; when James finally disclosed to his partner "my fiancée (...) disclosed to me that she had, uh, uh, been abused when she was a, a child as well, which I uh, hadn't known before”. Two (2) more men described learning that some of their friends had also been abused as children; for Christophe, finding out his friend had been a victim of CSA and knew other males who were also survivors gave him the authorization to speak up: "the fact that my friend (told me) that she had also been a victim, and that three of her ex-boyfriends, guys, (also had been abused), it sort of authorized me to talk about it" ${ }^{* *}$. For the men in the study, knowing they were not alone with their abuse experience helped break down barriers and facilitated disclosure.

\footnotetext{
** Quote translated from French to English
} 
Impact of various forms of media on disclosure. In total eight (8) men expressed having been impacted positively by hearing about the story of other men who had been sexually abused. Four (4) men spoke specifically about the beneficial impact they felt after reading the biography of other survivors. While four (4) other participants specifically spoke about viewing the stories of survivors on television; the Oprah Winfrey television episode that focused on male CSA and the impact it could have on the lives of men was highlighted as being pivotal in the disclosure and service seeking for three (3) of these men (1 Anglophone and 2 Francophones); Sam explained that "the Oprah Winfrey show started everything for me (...) when I watched the show, she said, (...) 'to begin the healing the first thing you have to do is tell'”. Ben similarly echoed the impact of this television episode for him " 200 men spoke up about their sexual abuse and that made me relive and accept the sexual abuse I had personally experienced in my childhood"**. For the fourth man, the Quebec-centered history of the Duplessis Orphans was cited as being important for him to understand he was not alone facing the difficulties linked to CSA.

\section{Disclosure Experiences}

While the experience of disclosure varied from one participant to another, several men had both positive and negative experiences sharing their abuse history with those around them. Positive experiences involved feeling supported by others, as well as being listened to and not being judged; while negative experiences involved being made fun of, ignored, blamed, and not believed.

Positive disclosure experiences. Only two (2) men expressed having solely had positive experiences disclosing. James disclosed for the first time to a counsellor, eventually to his parents, sister and spouse, and then later to the police as well as to several members of a CSA

\footnotetext{
** Quote translated from French to English
} 
survivors support group. He described exclusively positive experiences with disclosure despite having a huge sense of guilt regarding the abuse. His first disclosure appeared to pave the way to remove some of the blame he placed on himself:

I was quite nervous and embarrassed so I uh, ya know, didn't have a lot to say but (...) the counselor was definitely uh, was helpful, and just kind, (...) rewording things so that I could (...) really understand that it really, was really not my fault (...) I found that helpful.

Twelve (12) other participants conveyed that they had at least one positive disclosure experience. Four (4) men specifically spoke about the importance of being believed when disclosing; James talked about his experience disclosing to his family, and how beneficial being believed and listened to was: "the biggest help for me um, was, was having them believe me and uh, being okay with talking about it". Three (3) participants also explained the need to feel safe and have a trusting relationship with the person before they are able to disclose; Robert noted that he was planning on disclosing to others in the future, but needed first to ensure he could trust them: "there's a couple of other people that I'm, I'm going to uh, disclose to, but (only) when I've got enough confidence and trust in them that uh, it will be um... um... uh, accepted and understood". While establishing a trusting relationship takes time, it also allowed the participants to feel more secure in his choice of person to disclose to.

Negative disclosure experiences. Twelve (12) men also expressed having experienced at the very least, one negative disclosure experience throughout their live. For example Richard's grandmother attempted to silence him by warning him not to disclose to anyone else: "when we were at the hospital and I crawled up on her lap, and she told me never to tell a soul (about the abuse)". After that attempt at disclosure Richard waited 42 years before telling someone again. Sam, on the other hand, disclosed to his wife for the first time and received a very cold reaction; he explained that "she was kind of non-empathetic (...), it was like it was nothing to her, she 
treated like it was nothing, (...) she didn't seem to understand, or didn't seem to care”. Three (3) men specifically noted that they were not believed when they disclosed the abuse. One (1) man expressed that his discomfort with disclosing stemmed from the fact that he felt that disclosing his CSA history had the potential of identifying him as an easy target for other forms of abuse in the future. Two (2) other men noted that people were often uncomfortable hearing about disclosure, due to the emotionally challenging nature of the topic. For two (2) of the participants, their disclosure was used as a threat against them; in both cases, the men had disclosed to their spouses (now ex-spouses) and the women had used the information against them in arguments, sometimes even threatening to tell other people, as Daniel explained: "once I shared the fact that I had been sexually assaulted as a child, she would use that as a weapon - every time we had a fight or disagreement about something she would re-open that wound"**. Although negative disclosure experiences did not prevent the men in the sample from disclosing to others afterwards, it certainly caused them a great deal of pain, and in some cases regret.

Desire to protect others. Having experienced CSA made several men more sensitive to the possibility that other children could become victims. Six (6) participants noted a strong desire to protect kids. Jacob felt strongly that all adults held the responsibility of keeping the younger generation safe: “no young person, I don't care where they are, who they are, where they come from or what they are, no one should go through what I went through as a child". Since disclosing had been so challenging for him, James on the other hand expressed wanting the children in his family to know they could always confide in him:

I have one nephew who (I told) 'no matter what happens' and I said 'I will always believe you' and I said 'so if anything bad happens and you can't tell anybody, you can tell me' um, so I've been a bit hyper vigilant, um for watching out for, for him.

\footnotetext{
** Quote translated from French to English
} 
In essence James wanted to offer the kids close to him a sense that they would be heard and believed if they ever needed to disclose difficult events.

Support in a non-therapeutic context. In total thirteen (13) participants expressed having received some form of support from those close to them following their disclosure. Some men received support from more than one individual, while others received very strong support from some people but not from others. Relationships were found to be supportive when the men were listened to, were emotionally respected and were treated in a compassionate manner. Four (4) men expressed having received support from either one, or both of their parents. Christophe disclosed to both his parents that his uncle (his father's brother) had sexually abused him, and while they reacted differently, both were supportive:

(My dad) told me right away 'OK, you have to talk to the police' (...) yes, he's my dad and it goes without saying that he wants what is best for me (but) my mom was and still is very, I don't know exactly how to say this, supportive - she was present, that's it ${ }^{* *}$.

Five (5) other participants rather noted that their spouses had supported them emotionally.

Jeremy's wife was a great source emotional comfort for him since: "she was open - as if, huh, I mean, whew, there was no negative reaction, uh, she was a big help with all that"** For five (5) more men, it was their siblings that were supportive of them after they disclosed; while Daniel's older brother was unsure how to help he showed a great deal of consideration:

He was very understanding and listened to everything... he'd say 'I can't give you any advice because I have no experience in that, I can't tell you what to do' but it was clear that he was grateful that I had talked about it ${ }^{* *}$.

Two (2) men also received support from extended family members, while three (3) were supported by their friends.

\footnotetext{
** Quote translated from French to English
} 
While several participants were able to describe supportive situations, there were ten (10) men who noted not receiving the expected support from those close to them, outside of therapeutic relationships. Non-supportive relationships took place when following their disclosure the men were met with harsh or negative attitudes, were ridiculed, threatened or not believed, or were simply ignored. Five (5) men reported not receiving support from at least one, and in some cases both parents. Daniel's parents remained completely neutral, showing their son very little empathy: "so I told them and, uh, in the end their reaction was neutral, uh, uh, neither positive nor negative, and then they never spoke about it again" ${ }^{, * *}$. When disclosing to his parents Jean-Marc felt his father wanted him to keep quiet since the abuser was a family member:

I told my parents about it (...) and my father said 'that is your sister's husband' ... and for me that means shut up, keep your mouth closed, put up with it, that's how I understood it (...) And, now, everybody, the, the, the entire family, all of them know about it and nobody talks about it $(. .$.$) they don't believe it { }^{* *}$.

What hurt Jean-Marc the most was not that his father did not believe him, but rather that he did not seem to care about the abuse. Three (3) men mentioned not being supported by their siblings after having disclosed, Simon explained that: "my sister was a bit cold... a bit more distant" Three (3) men also specifically noted that their spouses were not supportive when they disclosed their CSA history; paradoxically the spouses of two (2) of these participants were themselves victims of sexual abuse. Extended family members were not supportive for three (3) of the men in the study. Finally, only two (2) men expressed not receiving support when disclosing to certain friends, while Philip did not always receive the support he was hoping for from his friends, he explained that:

\footnotetext{
** Quote translated from French to English
} 
Some of them just weren't ready to hear it, so, you know, I didn't push it, I told them it was $\mathrm{OK}$ and, you know, if they wanted to talk about it with me, they could come and see me and ask some questions ${ }^{* *}$.

Philip's sentiment demonstrates understanding of the emotional impact CSA disclosure could potentially have on others.

Experiences of non-disclosure. While disclosure experiences were not always easy, a few men noted that not disclosing was just as difficult; for four (4) men, the weight and burden of keeping the abuse secret was extremely difficult, and felt much like living a lie. Daniel, for example, noted how painful and lonely keeping the abuse hidden had been for him: "it's because, at the end of the line, what hurts the most is not the sexual abuse itself so much as having to keep it secret, to be all alone with the secret"**. Christophe expressed how not disclosing the abuse could lead to isolation as it created an invisible barrier with those around him: "when you have a secret, like a heavy burden on your shoulders, there is always a kind of wall between you and the rest of the world"** . Four (4) other men, held deep regrets about not disclosing the abuse to a specific person in their lives, Jacob, for example, explained how he would have liked to speak to his mother about the abuse: "I wish I would have been able to, uh, been open and honest with her, and, and, I also want, I also wonder why she didn't know or, uh, supposedly didn't know, and didn't do anything about it". For Jacob, regretting to disclose to his mother was also linked to trying to understand why she had never suspected or acted on the abuse that had taken place in their home.

Disclosing with ease. Although the process of disclosing CSA can be riddled with challenges, some men found themselves eager to share their abuse history. Five (5) men reported being able to disclose their abuse with ease as it had become part of their personal story, Martin

\footnotetext{
** Quote translated from French to English
} 
explained: "I ended up becoming used to, you know, telling that (disclosure) as part of my narrative, like it was part of my life". Similarly, Daniel explained that disclosing had become easy for him: "I'm used to telling my story so (it's not) hard anymore"**. Martin additionally made a distinction between disclosing to service providers versus disclosing to friends or loved ones:

I found a way of being able to kind of shut myself off from it and recount it, as opposed to every time living through it, you know (...) I guess it's like the analogy between a prostitute who's sleeping with people for money (or) actually sleeping with somebody who they care about.

Two (2) other men were so open about their history that they specifically expressed wanting to one day share their experience of CSA and disclose on a wider scale by writing an autobiography.

\section{Experiences with Services}

For the participants in the study, support services were often pivotal in their recovery. Services varied for each man, but often included individual counseling as well as support groups. As Daniel explained, the journey of obtaining services, although sometimes interrupted, often felt like a voyage leading him to a better self: "(I had to go many times for help) I see it like it's a journey... so I would start the journey again... every time, I start (my personal process) a little

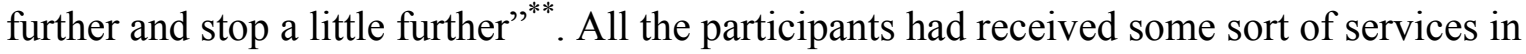
connection with their CSA, and were motivated by a number of different factors both to seek services and to continue using them.

Taking the first step. The power of popular media also extended beyond breaking the feeling of isolation and helped inform and motivate the men to access services. Six (6) men expressed having been motivated to obtain services only after viewing, either in the newspaper or

\footnotetext{
** Quote translated from French to English
} 
on television, information describing services for male CSA; Daniel for example, explained how finding out about CSA services for men on the news led him to seek help: "the director (of the organization that helps men who have been sexually abused as children) was on T.V... and immediately after seeing that I got in touch with them"**. Jean-Marc had a similar experience watching television: "I saw that (name of the organization) was for men only, for men (who had been sexually abused as children) and, you know, I wrote down the number, the telephone number and I called"** . The widespread accessibility of television proved to be a useful tool both to help break the taboo of male CSA and inform people of services. Six (6) men started to seek out services to address their CSA history mainly due to issues they were having in their lives, either with their personal relationships or in connection with their finances; for Martin, ensuring that his relationship did not suffer from his abuse was critical: "I sought out counselling because I wanted to make sure that, you know, as much as possible, I could continue working on myself, so that I was, I was the most beneficial partner I could be to my partner". Three (3) other men initially started to get help after having been referred to specialized services from other professionals. Seeking out services was not always a journey the men faced alone, five (5) participants expressed having been encouraged by their spouse, their family members or their friends to get help and find the necessary resources; Ben's brother played a critical role in encouraging him to get help: "I spoke to my brother and he suggested that, uh, a support group and I called them.... And my brother encouraged me to go to (name of the organization) and to continue going (when I started to experience challenges)",**.

A helping hand. While not a single question during the interview process specifically asked the men their level of satisfaction with the services they received, more than half spontaneously

\footnotetext{
** Quote translated from French to English
} 
described finding the specialized help they received to be extremely beneficial; Simon compared the assistance he received to a life-preserver "(those services) were like a life jacket for me" Six (6) men specifically expressed having had very positive experiences with CSA men's discussion and support groups since the participants were able to recognize their abuse experience in others; Martin talked about how he found a sense of community through his involvement in survivor groups "it's really empowering to hear all these different people's kind of perspective, how they've dealt with stuff $(\ldots)$ with the successes $(\ldots)$ and the trials". His words were echoed by Jacob: "it was a good experience because I was, I was in a group with other men that basically, they went through the same thing that I did, so it was easier to talk about". James found the group he attended useful to clarify several elements he had discussed with his therapist in individual sessions:

I found the group process quite (...) helpful and um made things make a lot more sense 'cause it was one thing when a counsellor says ya know 'that's normal and everybody feels that way' but to have a bunch of other guys around (...) saying the exact same thing, (...) it was uh definitely, definitely helpful.

Only one (1) man expressed not having found the groups to be helpful. Five (5) men also conveyed that they had had positive experiences of support during their individual therapy; while Sam was reluctant to speak to a therapist at first, the experience proved to be quite positive: "as far as I was concerned therapy was 'hokey', like nonsense, right? A waste of time, but it was actually incredible! (Laugh) It helped a lot, I was pleasantly pleased". Simon also described his relationship with his therapist as being extremely positive for him and his recovery: "he was, uh, very, very understanding, you know, uh, very, uh, human (he would say) 'take your time, go at

\footnotetext{
** Quote translated from French to English
} 
your own, uh, rhythm","** Despite the hardships faced by the men in the study, the proper support they received from professionals helped them grow as individuals.

Challenges of getting services. Despite all the positive elements that the men were able to pull out of their experiences accessing services for their CSA history, certain challenges were also evident. Five (5) participants explained that services were limited for men as society more often understood that victims of CSA were female and therefore directed much more resources to services for them; Serge was incensed about the lack of attention given to male survivors in our society, he explained:

All of the handouts and pamphlets concerning sexual abuse were about women and there were only resources for women in them (...) I think it is terrible that information coming from the government is so sexist when it comes to sexual abuse it does not encourage disclosure (...) I had the impression that society was literally denying that sexual abuse of men occurred, or at least minimized the abuse, turned it into something ordinary (...) our society is, uh, discriminatory when it comes to help ${ }^{* *}$.

Sam similarly felt that the services for women dominated the help available for victims of CSA: “there's lots available and lots known about what to do with women (but with the services for men they) don't even know what (they're) doing yet, somehow". The long waiting list to obtain services was also mentioned as being an important challenge to accessing help by three (3) men; Simon explained that "the waiting lists, they can be very long, sometimes, you know, several months, even a year"*** Governmental and organizational priorities in terms of CSA services as well as funding affected the men and therefore created several challenges for them to access services.

** Quote translated from French to English 


\section{Discussion}

The experiences of the participants in the study reflected the complex journey that takes place for men that disclose CSA and later seek services. The first theme addressed the impact of the abuse on the men, and was demonstrated through externalized and internalized issues as well as relationship challenges. The second theme examined disclosure trajectory and encompassed a wide range of experiences in terms of timeframe for first disclosure, as well as the different factors that hampered or encouraged disclosure, such as the social stigma and stereotypes regarding male CSA or finding validation in the CSA experiences of those close to them. The third theme focused on the actual disclosure experience of the participants and addressed the positive and negative experiences with disclosure, the level of support they received when they shared their story, as well as the impact not disclosing had on their lives. Finally, the fourth theme documented the journey of obtaining services for the men, which was often critical in their personal trajectories. Obtaining services was generally felt to be a positive experience, although often made challenging by the lack of resources.

\section{Impact of the Abuse on Various Spheres of the Men's Lives}

Although this research did not initially seek out to identify the impact of CSA on the lives of men, the participants nonetheless shared a great deal of information that generally reflected what is already well known in the CSA literature.

Externalized behavior. Anger and aggression were found to be evident in the narratives of the participants who expressed either a very direct anger at their abuser or simply a more generalized form of anger throughout their lives. Although anger could be found in the literature in both male and female samples, it appeared to disproportionately affect male victims (Alaggia and Millington, 2008; Denov, 2004; O'Leary, \& Gould, 2010; Staller, \& Nelson-Gardell, 2005). The desire to drown out the abuse through substance use was frequent amongst the participants 
and reflected a reality also found in the literature. Indeed the use of drugs and alcohol were found by several authors to be a common coping mechanism for CSA victims (Allagia and Millington, 2008; O’Leary, \& Gould, 2010; Valente, 2005). Another way the participants demonstrated externalized behaviors was through acting out during their childhood. Acting out was found to be a common manifestation and was a type of outlet for the victims (Hunter, 2011).

Internalized behaviors. Although gender patterns in CSA victims predict that men are more likely than women to develop externalized behaviors following CSA (Sorsoli, Kia-Keating, \& Grossman, 2008) several behaviors were also internalized by the participants in the study. While the emotional impact of CSA led only a couple of men in the study to withdraw socially and isolate themselves from others, several authors had previously identified isolation as a key component in the trajectory of CSA victims (Dorahy, \& Clearwater, 2012; Deering, \& Mellor, 2011; O'Leary, \& Gould, 2010). The discrepancy in the results may in part be due to the fact that all the participants in the study had either recently or were currently receiving services at the time of the research and were therefore not completely isolated. Self-esteem issues were also evident in the sample as a number of men described having struggled with self-worth at some point in their lives due to the abuse they suffered. Loss of self-esteem following CSA was also found to be relevant in the literature (Deering, \& Mellor, 2011; Valente, 2005). Issues surrounding anxiety were also evident in the sample as several men described suffering from various types of anxiety, ranging from generalized anxiety and PTSD, to difficulty sleeping. The literature on CSA supported claims for PTSD (Ullman, 2003) as well as generalized anxiety (Hunter, 2011; Deering, \& Mellor, 2011) and sleep disturbances (Chen, et al., 2010; Noll, Trickett, Susman, \& Putman, 2006).

Depression, suicidality and suicide attempts were all too common amongst the sample of men interviewed; which has also been highlighted by several authors in the past (Hunter, 2011; 
Deering, \& Mellor, 2011; Denov, 2004; Easton, Renner, \& O’Leary, 2013; Alaggia, \& Millington, 2008; Valente, 2005). The impact of CSA led a good number of men to struggle at some point in their lives with various common emotions such as embarrassment, guilt and shame. While embarrassment was mentioned slightly less often in the literature (Yousaf, Grunfeld, \& Hunter, 2013), guilt (Easton, et al., 2011; Ullman, 2003) and shame (Ullman, 2003; Deering, \& Mellor, 2011) were often highlighted as being common feelings for survivors of CSA, causing them frequently to either isolated themselves (Dorahy \& Clearwater 2012) or hold back disclosure (Hunter, 2011).

Stunted interpersonal skills. It has been established that forming close relationships was often found to be difficult for survivors on any level, whether it be with intimate partners, parents or children (Jonzon, \& Lindbland, 2004; Alaggia \& Millington, 2008; Dubé, et al., 2005).

Without a doubt most of the emphasis in the literature has been placed on issues surrounding romantic and sexual relations, which reflects the results found in this study since an overwhelming number of participants described various problems in their romantic lives, both with regards to forming and maintaining relationships, as well as with sexuality within these relationships. Some authors found concurring results and noted that CSA could lead survivors to suffer from sexual difficulties such as problems with intimacy, as well as fear or guilt during sexual encounters (Easton, et al., 2011; Ullman, 2003). Nevertheless, the vast majority of the literature rather highlighted the sexual deviance or dangerous behavior survivors often demonstrated later in life. Alaggia and Millington (2008) found that the men in their study suffered from numerous sexual challenges such as getting involved in the sex trade or the porn industry, being aggressive sexually towards women or simply being promiscuous. Other authors highlighted similar behaviors such as excessive or unprotected sexual encounters (Follette, et al., 2009), as well as sexual risk taking (Valente, 2005). Sexual difficulties also surfaced for the men 
abused by women, Denov (2004) noted that the participants had challenging relationships with the opposite sex, which in some cases translated to violent fantasies about women; Deering and Mellor (2011) similarly noted that being abused by a woman had a negative impact on the sexuality of all the male victims in their study, making them either excessively interested in sex, not finding it pleasurable or not being able to have sex and remaining celibate. In the current study, struggles with sexuality were common for the participants, however, only one mentioned a potentially dangerous sexual behavior (use of escorts), and while the literature seems to suggest that survivors of CSA may develop several risky sexual behaviors that was not the case for our sample. This may be due to the fact that our sample only included men who were receiving or had recently received help for their history of CSA, as opposed to other studies where participants were not always receiving services.

With regards to problems related to child rearing, the issues that surfaced were related to doubts regarding parenting skills, either with current or future children. Price-Robertson (2012) explained that while having children was anxiety provoking for some male victims, for others it was experienced as a form of healing. Difficulties in professional relationships as well financial struggles did surface during the interviews for a few of the men. While little has been written specifically regarding workplace challenges for survivors of CSA, it has been well established that maintaining positive relationships on any level is often challenging (Alaggia \& Millington, 2008). However, Ullman (2003) highlighted that financial struggles were amongst the multitude of consequences victims of CSA faced later in life.

\section{Disclosure Trajectory}

The disclosure trajectory of each man was as unique as his personal story of abuse. The first person the participants' chose to disclose to seemed to reflect the bond they felt with the individual more so than anything else, and included professionals, family members, spouses and 
close friends. The literature has identified disclosure as a 'process' thus clearly reflecting the complexity of the situation experienced by the victims, involving multiple levels of interacting influences rather than singular events that evolve in a linear fashion (Staller, \& Nelson-Gardell, 2005; Ahrens, et al., 2010; Alaggia, 2010). The individuality of disclosure trajectories has also been further recognized in the literature; first disclosures were generally found to be based on the level of comfort the victim felt with the other person (Follette, et al., 2009; Sorsoli, et al., 2008; Deering \& Mellor, 2011). One element however, did diverge somewhat from the literature; while children and teenagers are believed to disclose more often to friends than parents (Schönbucher, et al., 2012), at least half of the participants who disclosed before the age of 18 told their mothers first. Delaying disclosure was found to be quite common for victims of CSA, and while some tell a little later in childhood several will only disclose years later once they have reached adulthood (Alaggia, 2010; Alaggia, \& Kirshenbaum, 2005; Goodman-Brown, Edelstein, Goodman, Jones, \& Gordon, 2003; McElvaney, Greene, \& Hogan, 2012; O’Leary, \& Barber, 2008; Paine, \& Hansen, 2002; Ullman, 2003). The literature on delayed disclosure concurred with the results of the study since all the participants waited some amount of time before disclosing their abuse and only a minority of participants actually disclosed in childhood.

The invisibility of male CSA contributed to several men delaying their disclosure. Several men agreed that women were often seen as the sole victims of CSA, which led the participants to often feel marginalized in their experiences. Furthermore, a number of men in the sample often felt that masculine norms and stereotypes contributed to them keeping quiet about the abuse, as they feared judgement and ridicule. Fears of being labelled as a homosexual or as a potential child abuser were also present for the men in the sample. The participants that were abused by a woman also faced specific stereotypes that limited their disclosure. The literature focuses much more attention on the experiences of female victims, contributing to the mainstream belief that 
men are perpetrators of abuse and women of are victims, not abusers (Dorahy, \& Clearwater, 2012; Price-Robertson, 2012; Alaggia \& Millington, 2008). The dominant stereotypes found in the literature surrounding masculinity, strength, aggressiveness and dominance also concurred with the results of several other studies, and tended to overpower public opinion and contribute to men feeling that their history of abuse went against gender norms (Anderson, 2011; Alaggia, 2010; Conh, \& Zeichner, 2006; Grossman, Kia-Keating, \& Sorsoli, 2006; Sorsoli, et al., 2008). Similarly, homophobic notions surrounding male CSA perpetuate a climate in which victims delayed their disclosure to avoid negative labels (Alaggia, 2010; Davies, \& Rogers, 2006; Dorahy, \& Clearwater, 2012; Hunter, 2011; Paine, \& Hansen, 2002; Valente, 2005); fears of being labeled as a future child molester were also confirmed in the literature to be a concern for other male survivors (Alaggia, 2005; Price-Robertson, 2012).

Although the interviews did not set out to uncover information regarding the repression of CSA memories several participants spontaneously shared their personal experiences of forgetting about the abuse. Some participants described purposefully forgetting the abuse, while others mentioned repressed memories or flashbacks. The comments made by the participants regarding delayed memories fuel the controversial debate in the literature about the issue of recovered or repressed memories in the context of CSA (McNally, Perlman, Ristuccia, \& Clancy, 2006; Geraerts, Arnold, Lindsay, Merckelback, Jelicie, \& Hauer, 2006). While the idea of repressed memories often seems complex, Clancy and McNally (2005) noted that the normal process of memory could explain why some victims forget parts of the abuse or the abuse in its entirety and could be explained by conscious factors as well as regular memory processes.

For several men in the study, learning that friends or family members had themselves been victims of CSA facilitated their disclosure and helped bring down the barriers that led them to isolate themselves. Recognizing that others close to them had similar CSA experiences also 
helped reduce the stigma linked to the abuse. Although little information was available in the literature regarding the recognition of self in the experiences of others, it has been demonstrated that speaking to other victims, such as in the context of group settings, could have positive repercussion on survivors as it helped break down isolation and allowed them to share with others who had similar experiences (Hébert, \& Bergeron, 2007). Publicized stories of CSA, especially those involving well known public figures, also contributed to breaking the isolation, and taboo. Autobiographies, and television shows had the most impact on the participants and often even served as motivators to disclosure. In recent years slightly more attention has been given in the literature to the topic of media and CSA, however for the time being, the research generally focuses on prevention of CSA through the media (Self-Brown, et al., 2008), addresses how the media covers infamous CSA scandals (Mancini, \& Shields, 2014), or tackles victims' confidentiality during media coverage (Jones, Finkelhor, \& Beckwith, 2010). Hunter (2009) however did highlight that the disclosure of the experience of public figures, such as Oprah Winfrey, allowed other victims to feel comfortable admitting that their CSA had impacted them as well. Alaggia and Mishna (2014) also noted that several high profile cases involving male CSA have surfaced in North America in recent years exposing abuse both in organized sports and in religious sectors. While not directly linked to CSA, a study examining the impact of mass media on stigma and disclosure of HIV status, determined that when presented positively, the media could contribute to reducing stigma and potentially lead to more disclosure (Hutchinson, Mahlalela, \& Yukich, 2007), therefore suggesting that using positive media could help break stigma and reduce the taboo on topics otherwise rarely discussed. 


\section{Disclosure Experiences}

When deciding to disclose survivors can face both positive and negative reactions from others (Ahrens, et al., 2010). Although the positive aspects of disclosure are often overshadowed in the literature by the negative elements, forgetting to highlight the positive aspects that may surround disclosure contributes to the false belief that disclosing will always be a negative experience. Nonetheless, certain components can help create a more positive experience; feeling safe was found to be critical when disclosing (Alaggia, 2004; Staller, \& Nelson-Gardell, 2005), as well as being believed and comforted emotionally. These factors contributed to finding a disclosure experience to be more positive (Ullman, 2003). Schönbucher et al., (2012) found that when disclosure led to accessing proper services it was also often experienced positively. The results of this study indicated that having positive disclosure experiences was indeed quite possible. The majority of the men described at the very least having one positive disclosure experience throughout their on-going journey with disclosure. Feeling that they had been listened to, were believed, were safe, and were not judged by the person they disclosed to were some of the elements that led them to feel positively about their experience.

Despite wanting to identify the positive aspects of disclosure, the negative elements cannot be ignored either. Studies in which the authors solely found negative disclosure experiences amongst their participants were relatively frequent and illustrated the challenges that disclosure could present (Sorsoli, et al., 2008; Hunter, 2011). Negative disclosure experiences were marked with feelings of betrayal, or happened when the victims were not being believed (Hunter, 2011; Follette, et al., 2009), were blamed for the abuse or simply when the disclosure was met with indifference (Ullman, 2003; Jonzon, \& Lindbland, 2004). The results indicated that most men in the study also had at least one negative experience with disclosure. The emotional nature of the disclosure was enough to make some men feel it was a negative experience, while 
for others it was rather the fact that they had not been believed or that the person they had disclosed to had used their knowledge of the CSA as a threat.

Wanting to protect others was important for a number of the participants. Preventing future CSA or ensuring that the children around them would have a safe person to disclose to, appeared to be crucial to some of the men. The literature supported the notion that survivors often wanted to protect others; altruistic behaviors were found to help survivors of CSA make meaning of their abuse by turning it in to something more positive (Grossman, 2006; Ullman, Foynes, \& Tang, 2010). Receiving strong support from family, friends, and loved ones proved invaluable to several men in our study. While support varied from one participant to another, the majority of the men described having received some support from those around them after they disclosed. Unfortunately several participants were also able to note situations in which they had not been supported at all. The literature strongly suggested that the reaction and support individuals receive following their disclosure greatly impacts their personal process and outcome (Ullman, et al., 2010; Ullman, 2003).

Several theories for non-disclosure have been presented in the literature and barriers to disclosure have been examined on different levels by various authors, with most barriers being at the personal, relational, or sociocultural level (Alggia, 2010; Sorsoli, 2008; Deering, \& Mellor, 2011; Ullman, 2003; Hunter, 2011; O’Leary, \& Barber, 2008; Schönbucher, et al., 2012; Alaggia, 2005; Alaggia, \& Kirshenbaum, 2005; London, and al., 2008; Goodman-Brown, et al., 2003). A few participant specifically highlighted the intense weight they felt when they attempted to keep their abuse a secret. While the literature highlighted the pressure that some victims felt when trying to keep their abuse secret (Dorahy, \& Clearwater, 2012; Alaggia, 2005) the men in the sample rather spoke about how incredibly difficult it was to have such a large secret on their shoulders and to have no one to share it with. However, throughout their journey of multiple 
disclosures, a number of participants discussed feeling comfortable with their story to the point where disclosure was a smooth and straightforward process for them. The CSA literature unfortunately has yet to examine the narrative of survivors who disclose with ease, and instead generally focused on the fact that disclosure was an excruciatingly difficult obstacle to surmount (Alaggia, \& Millington, 2008; Hunter, 2011).

\section{Experiences with Services}

By virtue of the research design, all of the men in the sample received some sort of services for their CSA at some point in their lives, either through individual counseling or group sessions. The men were often motivated to get services for the first time either because they were experiencing a personal crisis or breakdown, or because they had seen some information about services through the media. Personal breakdowns or crises were found to sometimes motivate disclosure in adult CSA survivors (Alaggia, 2005) and therefore it seems conceivable that a difficult life situation would also push individuals to seek help. Several men sought out services only after having witnessed some information about organizations that helped male CSA in newspapers or on television, and credited them with helping them take the first step to get help. The impact of various media on the help-seeking behaviors of CSA survivors has unfortunately not been examined in the literature as of yet. It is therefore impossible to verify if these results concur with other studies. Overall, the men were quite satisfied with the services they received and felt they had contributed rather positively to helping them move forward and work through the consequences of CSA. Experiences of support and empowerment came through the narratives of the participants who received individual or group treatment. Very little information was available in the literature regarding the experiences of CSA survivors (even less so of men) who received services as adults. One study was however found; Chouliara et al., (2011) examined the 
experiences, of 13 adult survivors of CSA in Scotland (both men and women) that received individual counseling for their abuse history. Concurring with the results of our own study, the authors demonstrated that the participants felt safe to disclose, had established a trusting relationship with the workers, and felt the treatment helped them in their recovery.

Accessing the proper services was not always made easy for the men in the sample. As a general rule, the majority of the services were targeted for women and made finding services for men rather frustrating. These findings were supported by the literature, as it has been noted that the widespread efforts by feminist groups to publicize the scourge of sexual abuse and to promote the effective prevention of CSA has inadvertently categorized men as abusers rather than potential victims and has therefore limited the creation of services targeted to their specific needs (Davies, \& Rogers, 2006; Price-Robertson, 2012). The participants further noted that limited resources for men led to extremely long waiting lists as well as long commute times to reach organizations. The literature confirmed that help-seeking was found to be challenging for males, however it was generally due to social constructs of masculinity (Möller-Leimkühler, 2002; Cleary, 2012). Other challenges regarding service use for adult survivors included the emotional difficulties linked to the therapeutic work, continuity of care, as well as general availability of services, especially during crisis episodes (Chouliara et al., 2011). Although the participants in this study did not bring up the emotional difficulties the services could trigger, the shortage of available services was however highlighted as creating an additional barrier for the men to get proper support. A recent initiative led by the University of Ottawa is currently at the recruitment phase of a project also aimed helping bring recognition to the issue of male CSA. The Men's Project not only offers support of all types to men, but is also contributing to increase body of research on the topic (http://the mensproject.ca/). 


\section{Limitations}

The limitations for this study are quite similar to other research conducted with comparable populations. On one end, only 17 men were recruited in this project. The majority of

the studies involving male CSA have relatively small sample sizes due to the challenges linked to recruiting this vulnerable population (Grossman, et al., 2006; Sorsoli, et al., 2008). On another end, the recruitment characteristics only allowed for men who had recently received or were currently receiving services to participate in the study, which could have contributed to two important limitations. Firstly, as Dorahy and Clearwater (2012) explained, participants who receive help when participating in a study might be inclined to share their experience with disclosure more willingly than those who have never received services. Secondly, the disclosure experiences of men who have received help for their CSA is potentially quite different from the disclosure experiences of men who had never sought out services (Sorsoli, et al., 2008). As a result, the current findings cannot be generalized; as a qualitative study, the goal was never to produce findings that could be generalized on a larger scale, but rather to contribute to a relatively understudied topic in the field of sexual abuse. Another limitation that must be highlighted refers to the fact that the interview questions had not initially been set up to determine the experience of obtaining services for male CSA survivors and therefore certain elements might not have been explored fully.

\section{Future Research Opportunities}

As mentioned extensively throughout this thesis, research on male CSA is extremely limited. Several topics would therefore be worth studying further. Creating a similar research with a sample of men who have not yet sought services would be interesting as it could provide knowledge regarding disclosure experiences for this subset of male CSA victims. Indeed, the 
research on the disclosure experiences of men has only touched the surface of the topic and could be explored in much greater depth. Research on positive disclosure experiences as well as on the elements that lead survivors to feel more at ease disclosing should be further investigated in order to provide additional knowledge regarding how this difficult experience can become an encouraging step for survivors. Conducting outcome studies may also be worthwhile as it could help to thoroughly reflect the necessity of having sufficient services for male survivors by demonstrating the value of helping men cope with their history rather than allowing them to struggle alone.

\section{Implications for Practice and Policy}

The specialized services already in place for male CSA appeared to offer very beneficial services, although conducting program evaluations to assess the level of care of a wider sample might also be useful to servicing this population. The primary issue appears to relate to the availability of the services rather than their quality. Indeed, impossibly long waiting lists contribute to creating an atmosphere in which the needs of male survivors are deemed less important. A change in mentality starting at the policy level needs to happen in order to make services more commonly available; men need also to be recognized as potential survivors of CSA in the same way women have been. The welfare of abuse survivors needs to become more important to our elected officials as well, therefore the current trend of reducing social services of all types needs to be reversed if we wish to create more positive outcomes for CSA survivors. Awareness programs discussing CSA should always include a component focused on the male perspective and should be put in place, not solely in the hopes of preventing future abuse but also as a way of increasing consciousness regarding the issue at hand. These programs should be made available to professionals from various fields (social sciences, education, government 
offices) but most important of all should be made public through positive media awareness campaigns. Reliable governmental funding therefore needs to be put in place in order to expand the existing services as well as to create recurrent awareness programs.

\section{Conclusion}

This study demonstrated that male CSA disclosure narratives varied greatly from one individual to another; at the same time, all participants in the study experienced disclosure as a very multi-faceted, lengthy process. The research highlighted the impact of the abuse on the lives of the men; the trajectory they followed when disclosing; their experiences with disclosure; as well as their experiences obtaining services, as adults, for the CSA they had experienced. Above all else, this study aimed to illustrate the immense need to give a voice to men who have been victims of CSA as they are all too often forgotten by the literature and pushed aside by services that focus mainly on female survivors. The needs of male CSA survivors will only be truly addressed once we openly discuss the issue in practice and policy settings, as well as in the public sphere. 


\section{References}

Alaggia, R., Mishna., R. (2014). Self psychology and male child sexual abuse: Healing relational betrayal. Clinical Social Work Journal, 42, 41-48. doi: 10.1007/s10615-013-0453-2

Ahrens, C.E., Stansell, J., \& Jennings, A. (2010). To tell or not tell: The impact of disclosure on sexual assault survivors' recovery. Violence and Victims, 25, 631-648. doi: 10.1891/08866708.25.5.631

Alaggia, R. (2010). An ecological analysis of child sexual abuse disclosure: Considerations for child and adolescent mental health. Journal of Canadian Academy of Child and Adolescent Psychiatry, 19, 32-39. Retrieved from: http://www.ncbi.nlm.nih.gov/pmc/articles/PMC2809444/

Alaggia, R. (2004). Many ways of telling: Expanding conceptualizations of child sexual abuse disclosure. Child Abuse \& Neglect, 28, 1213-1227. doi:10.1016/j.chiabu.2004.03.016

Alaggia, R. (2005). Disclosing the trauma of child sexual abuse: A gender analysis. Journal of Loss and Trauma, 10, 453-470. doi:10.1080/15325020500193895

Alaggia, R. \& Kirshenbaum, S. (2005). Speaking the unspeakable: Exploring the impact of family dynamics on child sexual abuse disclosures. Families in Society: The Journal of Contemporary Social Services, vol. 86, 227-234. doi: 10.1606/1044-3894.2457

Alaggia, R., \& Millington, G. (2008). Male child sexual abuse: A phenomenology of betrayal. Journal of Clinical Social Work, 36, 265-275. doi: 10.1007/s10615-007-0144-y

Anderson, T.H. (2011). Against the wind: Male victimization and the ideal of manliness. Journal of Social Work, 13, 231-247. doi: 10.1177/1468017311410002

Bedar-Gilligan, M., Jaeger, J., Echiverri-Cohen, A., \& Zoellner, L.A. (2012). Individual differences in trauma disclosure. Journal of Behavior Therapy and Experimental Psychiatry, 43, 716-723. doi:10.1016/j.jbtep.2011.10.005

Carr, E., \& Worth, A. (2001). The use of telephone interview for research. NT Research, 6, 511524. doi: 10.1177/136140960100600107

Chen, L.P., Murad, M.H, Para, M.L., Colbenson, K.M., Sattler, A.L., Goranson, E.N., ... Zirakzadeh, A. (2010). Sexual abuse and lifetime diagnosis of psychiatric disorder: Systematic review and meta-analysis. Mayo Clinic Proceedings, 85, 618-629. doi: 10.4065/mcp.2009.0583

Chouliara, Z., Karatzias, T., Scott-Brien, G., Macdonald, A., MacArthur, J., \& Frazer, N. (2011). Talking therapy services for adult survivors of childhood sexual abuse (CSA) in Scotland: 
Perspectives of service users and professionals. Journal of Child Sexual Abuse, 20, 128156. doi: 10.1080/10538712.2011.554340

Clancy, S.A., \& McNally, R.J. (2005). Who needs repression? Normal memory processes can explain 'forgetting' of childhood sexual abuse. The Scientific Review of Mental Health Practice, 4, 66-73. Retrieved from: http://psycnet.apa.org/psycinfo/2008-00021-009

Cleary, A. (2012). Suicidal action, emotional expression, and the performance of masculinities. Social Science \& Medicine, 74, 498-505. doi: 10.1016/j.socscimed.2011.08.002

Conh, A., \& Zeichner, A. (2006). Effects of masculine identity and gender role stress on aggression in men. Psychology of Men \& Masculinity, 7, 179-190. doi: 10.1037/15249220.7.4.179

Creswell, J. W. (2007). Five qualitative approaches to inquiry. Qualitative inquiry \& research design, choosing among five approaches, second edition, 53-84, Sage Publication, Inc.

Crosson-Tower, C. (2008). The sexual abuse of children. In Understanding Child Abuse and Neglect $7^{\text {th }}$ Edition, 121-151, Boston, MA, Pearson.

Currie, J., \& Spatz Widom, C. (2010). Long-term consequences of child abuse and neglect on adult economic well-being. Child Maltreatment, 15, 111-120. doi:

$10.1177 / 1077559509355316$

Davies, M. \& Rogers, P. (2006). Perception of male victims in depicted sexual assaults: A review of literature. Aggression and Violent Behavior, 11, 367-377. doi:

10.1016/j.avb.2006.01.002

Deering, R., \& Mellor, D. (2011). An exploratory qualitative study of the self-reported impact of female-perpetrated childhood sexual abuse. Journal of Child Sexual Abuse, 20, 58-76. doi: 10.1016/j.avb.2006.01.002

Denov, M. (2004). The long-term effects of child sexual abuse by female perpetrators: A qualitative study of male and female victims. Journal of Interpersonal Violence, 19, 1137-1156. doi: 10.1177/0886260504269093

Diamanduros, T., Cosentino, C.E., Tysinger, P.D., \& Tysinger, J.A. (2012). Theoretical perspective of male sexual abuse: Conceptualization of a case study. Journal of Child Sexual Abuse, 21, 131-154. doi: 10.1080/10538712.2012.659804

Dorahy, M.J., \& Clearwater, K. (2012). Shame and guilt in men exposed to childhood sexual abuse: A qualitative investigation. Journal of Child Sexual Abuse, 21, 155-175. doi: $10.1080 / 10538712.2012 .659803$

Dube, S. R., Anda, R. F., Withfield, C. L., Brown, D.W., Felitti, V.J., Dong, M., \& Giles, W. H. (2005). Long-term consequences of childhood sexual abuse by gender of victim. 
American Journal of Preventative Medicine, 28, 430-438. doi:

10.1016/j.amepre.2005.01.015

Easton, S.D., Coohey, C., O’Leary, P., Zhang, Y., \& Hua, L. (2011). The effect of childhood sexual abuse on psychosexual functioning during adulthood. Journal of Family Violence, 26. 41-50. doi: 10.1007/s10896-010-9340-6

Easton, S.D., Renner, L.M., \& O’Leary, P. (2013). Suicide attempts among men with histories of child sexual abuse: Examining abuse severity, mental health, and masculine norms. Child Abuse and Neglect, 6, 380-387. doi: 10.1016/j.chiabu.2012.11.007

Easton, S.D. (2013). Disclosure of child sexual abuse among adult male survivors. Clinical Social Work Journal, 41, 344-355. doi: 10.1007/s10615-012-0420-3

Fater K., \& Mullaney, J.A. (2000). The lived experience of adult male survivors who allege childhood sexual abuse by clergy. Issues in Mental Health Nursing, 21, 281-295. doi:10.1080/016128400248095

Fergusson, D.M., McLeod, G.F.H, \& Horwood, L. J. (2013). Childhood sexual abuse and adult developmental outcomes: Findings from a 30-year longitudinal study in New Zealand. Child Abuse \& Neglect, 9, 664-674. doi: 10.1016/j.chiabu.2013.03.013

Finkel, M.A. (2012). Children's disclosures of child sexual abuse. Pediatric Annals, 41, 1-6. doi: $10.3928 / 00904481-20121126-10$

Follette, V.M., La Bash, A.J., \& Sewell, M.T. (2009). Adult disclosure of history of childhood sexual abuse: Implications for behavioral psychotherapy. Journal of Trauma and Dissociation, 11, 228-243. doi: 10.1080/15299730903502953

Galdas, P., Cheater, F., \& Marshall, P. (2004). Men and health help-seeking behaviour: literature review. Journal of Advanced Nursing, 49, 616-623. doi: 10.1111/j.1365-

2648.2004.03331.x

Geraerts, E., Arnold, M.M., Lindsay, D.S., Merckelback, H., Jelicie, M., \& Hauer, B. (2006). Forgetting of prior remembering in persons reporting recovered memories of childhood sexual abuse. Psychological Science, 17, 1002-1008. doi: 10.1111/j.14679280.2006.01819.x

Goodman-Brown, T.B., Edelstein, R.S., Goodman, G.S., Jones, D.PH., \& Gordon, D.S. (2003). Why children tell: A model of children's disclosure of sexual abuse. Child Abuse \& Neglect, 27, 525-540. doi: 10.1016/S0145-2134(03)00037-1

Grossman, F.K., Kia-Keating, M., \& Sorsoli, L. (2006). A gale force wind: Meaning making by male survivors of childhood sexual abuse. American Journal of Orthopsychiatry, 76, 434443. doi: $10.1037 / 0002-9432.76 .4 .434$ 
Hartill, M. (2009). The sexual abuse of boys in organized male sports. Men and Masculinities, 12, 225-249. doi: 10.1177/1097184X07313361

Hébert, M., \& Bergeron, M. (2007). Efficacy of a group intervention for adult women survivors of sexual abuse. Journal of Child Sexual abuse, 16, 37-61. doi: 10.1300/J070v16n04_03

Hébert, M., Tourigny, M., Cyr, M., McDuff, P., \& Joly, J. (2009). Prevalence of childhood sexual abuse and timing of disclosure in a representative sample of adults from Quebec. The Canadian Journal of Psychiatry, 54, 631-636. Retrieved from: http://europepmc.org/abstract/MED/19751552

Holt, A. (2010). Using the telephone for narrative interviewing: a research note. Qualitative Research, 10, 113-121. doi: 10.1177/1468794109348686

Hornor, G. (2010). Child sexual abuse: consequences and implications. Journal of Pediatric Health Care, 24, 358-363. doi: 10.1016/j.pedhc.2009.07.003

Hunt, M.R. (2009). Strengths and challenges in the use of interpretive description: Reflections arising from a study of the moral experience of health professionals in humanitarian work. Qualitative Health Research, 19, 1284-1292. doi: 10.1177/1049732309344612

Hunter, S.H. (2011). Disclosure of child sexual abuse as a life-long process: implications for health professionals. The Australian and New Zealand Journal of Family Therapy, 2, 159172. doi: 10.1375/anft.32.2.159

Hunter, S.H. (2009). Beyond surviving: Gender difference in response to early sexual experiences with adults. Journal of Family Issues, 30, 391-412. doi: 10.1177/0192513X08321493

Hutchinson, P.L., Mahlalela, X., \& Yukich, J. (2007). Mass media, stigma, and disclosure of HIV test results: multilevel analysis in the Eastern Cape, South Africa. AIDS Education and Prevention, 19, 489-510. doi: 10.1521/aeap.2007.19.6.489

Jones, L.M., Finkelhor, D., \& Beckwith, J. (2010). Protecting victims' identity in press coverage of child victimization. Journalism, 11, 347-367. doi: 10.1177/1464884909360925

Jonzon, E. \& Lindbland, F. (2004). Disclosure, reactions and social support: Findings from a sample of adult victims of child sexual abuse. Child Maltreatment, 9, 190-200. doi: $10.1177 / 1077559504264263$

Kia-Keating, M., Grossman, F.K., Soroli, L., \& Epstein, M. (2005). Containing and resisting masculinity: narratives of renegotiation among resilient male survivors of childhood sexual abuse. Psychology of men \& Masculinity, 6, 169-185. doi: 10.1037/15249220.6.3.169 
Kuehnle, K., \& Connell, M. (2010). Child sexual abuse suspicions: treatment considerations during investigation. Journal of Child Sexual Abuse, 19, 554-571. doi:

$10.1080 / 10538712.2010 .512554$

London, K., Bruck, M., Wright, D.B., \& Ceci, S.J. (2008). Review of the contemporary literature on how children report sexual abuse to others: findings, methodological issues, and implications for forensic interviewers. Journal of Memory, 16, 29-47. doi:

$10.1080 / 09658210701725732$

Mackenzie, C.S., Gekoski, W.L., \& Knox, V.J. (2006). Age, gender, and the underutilization of mental health services: the influence of help-seeking attitudes. Aging \& Mental Health, 10, 574-582. doi: 10.1080/13607860600641200

Mahalik, J., Good, G.E., \& Englar-Carlson, M. (2003). Masculinity scripts, presenting concerns, and help seeking: implications for practice and training. Professional Psychology,

Research and Practice, 34, 123-131. doi: 10.1037/0735-7028.34.2.123

Mancini, C., \& Shields, R.T. (2014). Notes on a (sex crime) scandal: The impact of media coverage of sexual abuse in the Catholic Church of public opinion. Journal of Criminal Justice, 42, 221-232. doi: 10.1016/j.jcrimjus.2013.06.006

McElvaney, R., Greene, S., \& Hogan, D. (2012). Containing the secret of child sexual abuse. Journal of Interpersonal Violence, 27, 1155-1175. doi: 10.1177/0886260511424503

McNally, R.J., Perlman, C.A., Ristuccia, C.S., \& Clancy, S. (2006). Clinical characteristic of adults reporting repressed, recovered, or continuous memories of childhood sexual abuse. Journal of Consulting and Clinical Psychology, 74, 237-242. doi: 10.1037/0022006X.74.2.237

Modelli, M.E.S., Galvao, M.F. \& Pratesi, R. (2012). Child sexual abuse. Forensic Science International, 217, 1-4. doi: 10.1016/j.forsciint.2011.08.006

Möller-Leimkühler, A.M. (2002). Barriers to help-seeking by men: a review of sociocultural and clinical literature with particular reference to depression. Journal of Affective Disorders, 71, 1-9. doi: 10.1016/S0165-0327(01)00379-2

Muller, E.S., \& Dowling, M. (2008). Mental health consequences of child sexual abuse. British Journal of Nursing, 17, 1428-1433. Retrieved from:

http://web.b.ebscohost.com/ehost/pdfviewer/pdfviewer?sid=9ba85eca-3362-4f8e-a966cf35f0b66c87\%40sessionmgr198\&vid $=2 \&$ hid $=114$

Musselwhite, K., Cuff, L., Mcgregor, L., \& King, K.M. (2007). The telephone interview is an effective method of data collection in clinical nursing research: A discussion paper. International Journal of Nursing Studies, 44, 1064-1070. doi:

10.1016/j.ijnurstu.2006.05.014 
Noll, J.G., Trickett, P.K., Susman, E.J., \& Putman, F.W. (2006). Sleep disturbances and childhood sexual abuse. Journal of Pediatric Psychology, 31, 467-480. doi: 10.1093/jpepsy/jsj040

Novick, G. (2008). Is there a bias against telephone interview in qualitative research? Research in Nursing \& Health, 31, 391-398. doi: 10.1002/nur.20259

O’Leary, P. (2009). Men who were sexually abused in childhood: Coping strategies and comparisons in psychological functioning. Child Abuse \& Neglect, 33, 471-479. doi: 10.1016/j.chiabu.2009.02.004

O’Leary, P., \& Barber, J. (2008). Gender differences in silencing following childhood sexual abuse. Journal of Child Sexual Abuse, 17, 133-143. doi: 10.1080/10538710801916416

O’Leary, P., \& Gould, N. (2010). Exploring coping factors amongst men who were sexually abused in childhood. British Journal of Social Work, 40, 2669-2686. doi: 10.1093/bjsw/bcq098

Padgett, D. (2008). Qualitative methods in social work research. Sage Publications, Inc.

Paine, M.L., \& Hansen, D.J. (2002). Factors influencing children to self-disclose sexual abuse. Clinical Psychology Review, 22, 271-295. doi: 10.1016/S0272-7358(01)00091-5

Patihis, L., Ho, L.Y., Tingen, I.W., Lilienfeld, S.O., \& Loftus, E.F. (2013). Are the 'memory wars' over? A scientist-practitioner gap in beliefs about repressed memory. Psychological Science, X, 1-12. doi: 10.1177/0956797613510718

Plummer, C., \& Eastin, J. (2007). System intervention problems in child sexual abuse investigations the mothers' perspectives. Journal of Interpersonal Violence, 22, 775-787. doi: $10.1177 / 0886260507300753$

Price-Robertson, R. (2012). Child sexual abuse, masculinity and fatherhood. Journal of Family Studies, 18, 130-142. Retrieved from: http://search.proquest.com/docview/1319253234?accountid=12339

Rasmusson, B. (2010). Children's advocacy centers (Barnahus) in Sweden: experiences of children and parents. Child Ind. Res., 4, 301-321. doi: 10.1007/s12187-010-9094-y

Saladaña, J. (2013). The coding manual for qualitative researchers, second edition. Sage Publications, Ltd.

Sanghara, K.K, \& Wilson, J.C. (2006). Stereotypes and attitudes about sexual abuser: A comparison of experience and inexperienced professionals in sex offender treatment. Legal and Criminological Psychology, 11, 229-244. doi: 10.1348/135532505X68818 
Schönbucher, V., Maier, T., Mohler-Kuo, M., Schnyder, U., \& Landolt, M.A. (2012). Disclosure of child sexual abuse by adolescents: a qualitative in-depth study. Journal of

Interpersonal Violence, 27, 3486-3513. doi: 10.1177/0886260512445380

Self-Brown, S., Rheingold, A.A., Campbell, C., \& De Arellano, M.A. (2008). A media campaign prevention program for child sexual abuse community members' perspectives. Journal of Interpersonal Violence, 23, 728-743. doi: 10.1177/0886260507313946

Sorsoli, L., Kia-Keating, M., \& Grossman, F.K. (2008). "I keep that hush-hush": Male survivors of sexual abuse and the challenges of disclosure. Journal of Counseling and Psychology, 55, 333-345. doi: 10.1037/0022-0167.55.3.333

St-George, S. (2010). Applied interpretation: A review of Interpretive Description by Sally Thorne. The Qualitative Report, 15, 1624-1628. Retrieved from: http://www.nova.edu/ssss/QR/QR15-6/stgeorge.pdf

Staller, K.M., \& Nelson-Gardell, D. (2005). “A burden in your heart”: Lessons of disclosure from female preadolescent and adolescent survivors of sexual abuse. Child Abuse \& Neglect, 29, 1415-1432. Retrieved from: http://www.ncbi.nlm.nih.gov/pubmed/16289689

Starks, H., \& Brown Trinidad, S. (2007). Choose your method: a comparison of phenomenology, discourse analysis and grounded theory. Qualitative Health Research, 17, 1372-1380. doi: $10.1177 / 1049732307307031$

Stolenborgh, M., Van, Ijzendoorm, M.H., Euser, E.M., \& Bakermans-Kranenburg, M.J. (2011). A global perspective of child sexual abuse: Meta-analysis of prevalence around the world. Child Maltreatment, 16, 79-101. doi: 10.1177/1077559511403920

Sturges, J.E., \& Hanrahan, K.J. (2004). Comparing telephone and face-to-face qualitative interviewing: a research note. Qualitative Research, 4, 107-118. doi: $10.1177 / 1468794104041110$

Tavker, P., \& Hansen, D. (2011). Interventions for families victimized by child sexual abuse: clinical issues and approaches for child advocacy center-based services. Aggression \& Violent Behavior, 16, 188-199. doi: 10.1016/j.avb.2011.02.005

Thorne, S. (2000). Data analysis in qualitative research. Evidence Based Nursing, 3, 68-70. doi:10.1136/ebn.3.3.68

Thorne, S. (2008). Interpretive description. Left Coast Press, Inc.

Thorne, S., Reimer Kirkman, S., \& O'Flynn-Magee, K. (2004). The analytic challenge in interpretive description. International Journal of Qualitative Methods, 3, 1-11. Retrieved from: http://www.ualberta.ca/ iiqm/backissues/3_1/pdf/thorneetal.pdf 
Tourigny, M., \& Baril, K. (2011). Les agressions sexuelles durant l'enfance, ampleur et facteur de risque. In M. Hébert, M. Cyr, \& M. Tourigny (Eds.), L'agression sexuelle envers les enfants, tome 1. (pp. 7-50). Presses de l'Université du Québec.

Ullman, S.E. (2003). Social reactions to child sexual abuse disclosure: A critical review. Journal of Child Sexual Abuse, 12, 89-121. Retrieved from:

http://www.ncbi.nlm.nih.gov/pubmed/16221661

Ullman, S.E., Foynes, M.M., \& Tang, S.S.S. (2010). Benefits and barriers to disclosing sexual trauma: A contextual approach. Journal of trauma \& Dissociation, 11, 127-133. doi: 10.1080/15299730903502904

Valente, S.M. (2005). Sexual abuse of boys. Journal of Child and Adolescent Psychiatric Nursing, 18, 10-16. doi: 10.1111/j.1744-6171.2005.00005.x

Whittier Newton, A., \& Vandeven, A. M. (2010). The role of the medical provider in the evaluation of sexually abused children and adolescents. Journal of Child Sexual Abuse, 19, 669-686. doi: 10.1080/10538712.2010.523448.

Yancey, C.T., \& Hansen, D.J. (2010). Relationship of personal, familial, and abuse-specific factors with outcome following childhood sexual abuse. Aggression and Violent Behavior, 15, 410-421. doi: 10.1016/j.avb.2010.07.003

Yousaf, O., Grunfeld, E.A., \& Hunter, M.S. (2013). A systematic review of the factors associated with delays in medical or psychological help-seeking among men. Health Psychology Review, $X, 1-13$. doi: 10.1080/17437199.2013.840954 


\section{Appendix A}

Pamphlet and poster that have been used in the recruitment 


\section{Disclosure Pathways}

We are looking for men and women 19 years old or above who experienced child sexual abuse in their history and who are currently receiving, or have recently received, services for their victimization.
To participate in this study, leave a message for Anya McDonald at 1-855-461-6715

Delphine Collin-Vézina, PhD

Principal Investigator

Canadian Research Chair in Child Welfare

Assistant Professor,

School of Social Work, McGill University

\section{McGill}

\section{Disclosure Pathways}

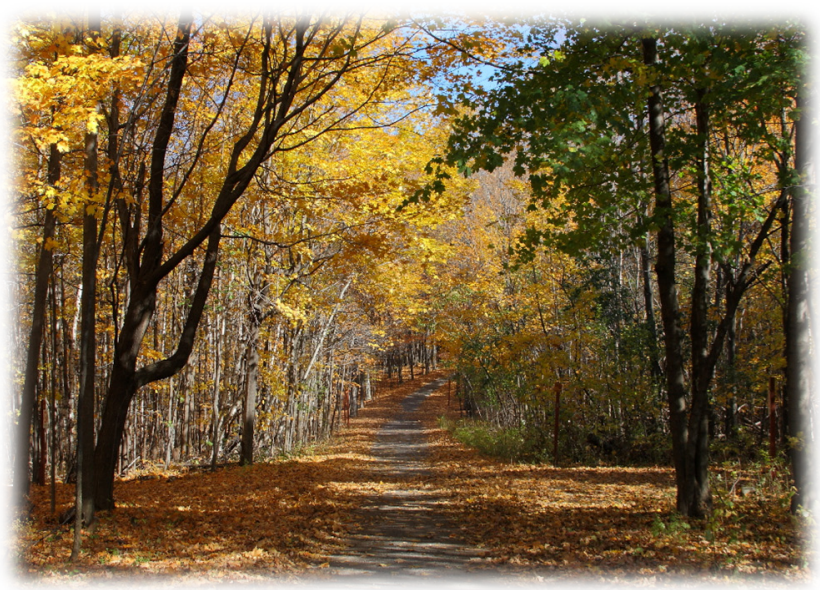

What are the factors that promote or inhibit disclosure of child sexual abuse?

Research Project

\section{McGill}




\section{What is the goal of this study?}

This study seeks to better understand factors that promote or inhibit disclosure of child sexual abuse.

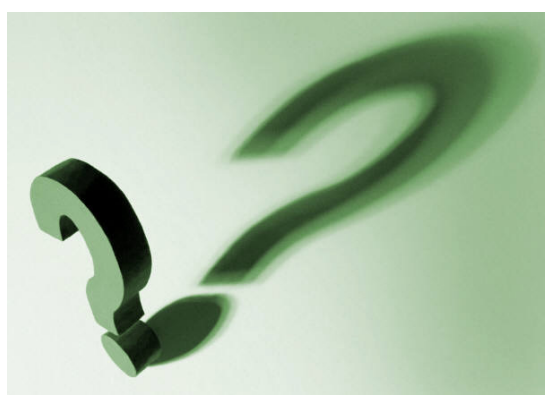

\section{What will I have to do if I agree to participate in this study?}

Your participation will comprise of a 1-time telephone interview that will be about 60 minutes long.

\section{Why should I participate in this study?}

By participating to this study, you will enable us to better understand factors promoting or inhibiting disclosure of child sexual abuse.

We hope that by sharing your experiences and involving you in the research process, we will be able to give a voice to you and other survivors and have this voice influence and encourage practice and policy change to better support survivors and better protect children.

To compensate your time, a twenty-dollar gift card (\$20) for Tim Hortons restaurants will be given to you.
By giving a voice to child sexual abuse survivors, this study hopes to bring to light the factors that are likely to promote or inhibit the disclosure processes. 
Research Project - Disclosure Pathways

\section{What are the factors that promote or inhibit disclosure of child sexual abuse?}

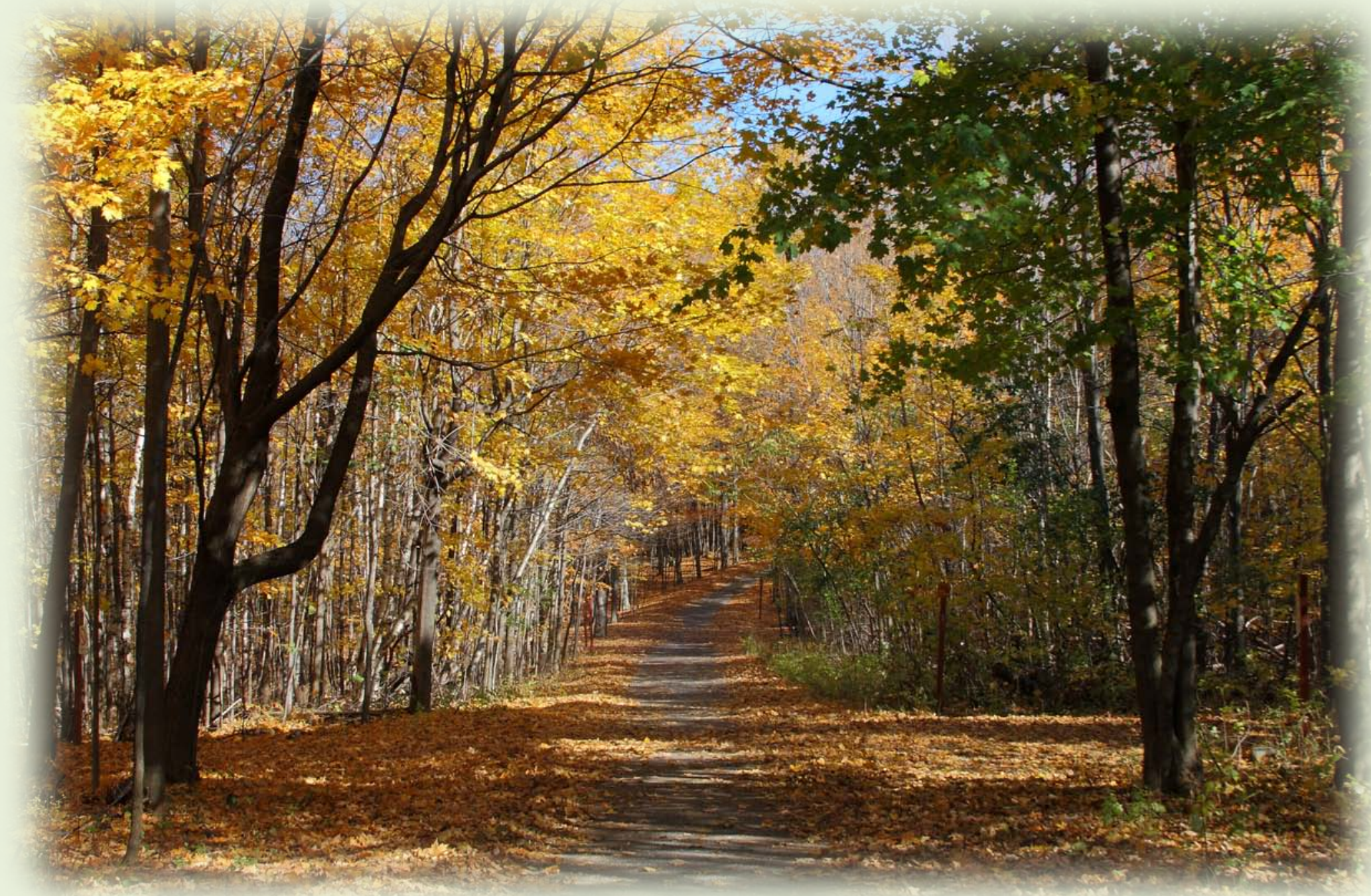

Are you a man or a woman above the age of 19 who experienced child sexual abuse in their history? Are you currently receiving or have you recently received services for your victimization?

Would you be interested in sharing your disclosure experiences?

By giving a voice to child sexual abuse survivors, this study hopes to bring to light the factors that are likely to promote or inhibit the disclosure processes.

Your participation will comprise of a 1-time telephone interview that will be about 60 minute long. Compensation will be given for participation in the form of a twenty-dollar gift card for Tim Hortons.

If you are interested in participating or would like more information, please leave a message for Anya McDonald, research assistant for this project, at 1-855-461-6715.

Delphine Collin-Vézina, PhD, Principal investigator, Canadian Research Chair in Child Welfare Assistant Professor, School of Social Work, McGill University

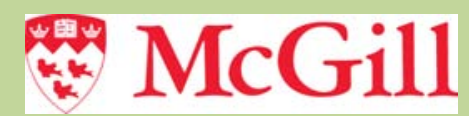




\section{Appendix B}

Consent Form

\section{Research Project Sexual Abuse Experiences: Exploration of Factors that Promote or Inhibit Disclosure}

Name of researchers: Dr. Delphine Collin-Vézina, Principal Investigator Dr. Nico

Trocmé

Dr. Christine Walsh Dr. Nicole Ives Dr. Harriet MacMillan

Funding Sponsor: Social Sciences and Humanities Research Council

Purpose of the study: The purpose of this project is to explore the processes by which child sexual abuse survivors disclose their abuse experiences, as well as the factors that promote or inhibit these processes.

Study Procedures: To examine this question, the project will use a semi-structured interview schedule to conduct qualitative interviews with adult survivors of child sexual abuse about their disclosure experience. The interview is expected to last up to 60 minutes and will take place over the phone.

Potential benefits and risks: Your participation will contribute to the advancement of knowledge through a better understanding of the disclosure process. There is potential for practice and policy changes. There is minimal risk for the participants. However, please note that some questions may raise uncomfortable feelings or emotions related to past experiences. You can choose to refuse to answer any questions at any time without justification.

Voluntary participation: Your participation in the research study is entirely voluntary. Your choice of whether or not to participate will not influence your future relations with McGill University or with the organization you are receiving services from. At any particular point in the study, you may refuse to answer any particular question or stop participation altogether. You may freely ask questions about this authorization agreement now or at any time.

Confidentiality: All information obtained during the study will be kept strictly confidential. After the interviews are completed, only the principal investigator, myself and another research assistant from the research team will have access to your personal information. The other investigators listed above will not have access to your identifiable data. Your name and other personal identifying information will never be used in any reports, presentations or publications. Please note, however, that confidentiality is limited if there is a risk that you are a danger to yourself or others. Actions taken will depend on the assessment of risk done by the interviewer. Potential actions include contacting the participant's counselor and calling the emergency services. 
Audiotape Recordings: In order to conduct this research, we are asking your permission to digitally record what is said during the interview for data analysis purposes only.

If anything causes you concern, or if you have questions, you may contact the principal investigator of the study, Dr. Delphine Collin-Vezina at (514) 398-7058 or myself, (Name of research assistant) at XXX- XXXX.

Also, this research was approved by the McGill University Research Ethics Board. If you have any questions or concerns about your rights or welfare as a participant in this study, please contact the McGill Research Ethics Officer at 514-398-6831 who is independent of the investigator and works to protect participants' rights.

Based on the consent that was read to me, I agree to participate in this study.

\section{[ ]Yes [ ] No}

I agree to be recorded.

\section{[ ]Yes [ ] No}

Name of Participant:

Signature of the participant: Date:

Signature of McGill Researcher:

Date: 
Appendix C

Ethics Approvals 


\section{McGill}

Research Ethics Board Office

James Administration Bldg.

845 Sherbrooke Street West. Rm 429

Montreal, QC H3A 0G4
Tel: (514) 398-6831

Fax: (514) 398-4644

Website: www.mcgill.ca/research/researchers/compliance/human/

\section{Research Ethics Board II \\ Certificate of Ethical Acceptability of Research Involving Humans}

REB File \#: 101-0713

Project Title: Experiences of Male Child Sexual Abuse Survivors who Disclosed their Abuse

Principal Investigator: Charlotte Gagnier Department: School of Social Work

Status: Master's Student $\quad$ Supervisor: Prof. D. Collin-Vezina

Funding Agency/Title: SSHRC "Decline in Sexual Abuse Cases Investigated by the Canadian Child Welfare System: Exploration of Potential Explanations" (PI: Collin-Vezina)

Approval Period: July 30, 2013 to July 29, 2014

The REB-II reviewed and approved this project by delegated review in accordance with the requirements of the McGill University Policy on the Ethical Conduct of Research Involving Human Participants and the Tri-Council Policy Statement: Ethical Conduct for Research Involving Humans.

Deanna Collin

Research Ethics Administrator

* All research involving human participants requires review on an annual basis. A Request for Renewal form should be submitted 2-3 weeks before the above expiry date.

* When a project has been completed or terminated a Study Closure form must be submitted.

* Should any modification or other unanticipated development occur before the next required review, the REB must be informed and any modification can't be initiated until approval is received. 


\section{McGill}

Research Ethics Board Office

McGill University

James Administration Bldg, room 429

845 Sherbrooke St West

Montreal, QC H3A 2T5
Tel: (514) 398-6831

Fax: (514) 398-4644

Ethics website:www.mcgill.ca/research/researchers/compliance/human/

\section{Research Ethics Board II \\ Certificate of Ethical Acceptability of Research Involving Humans}

REB File \#: 370-0311

Project Title: Sexual Abuse Experiences: Exploration of Factors that Promote or Inhibit Disclosure

Principal Investigator: Prof. Delphine Collin-Vézina Department: Social Work

Co-Investigators/Other Researchers: Nico Trocme, Christine Walsh, Nicole Ives, Harriet MacMillan

Funding Agency/Title: SSHRC / "Decline in Sexual Abuse Cases Investigated by the Canadian Welfare System: Exploration of Potential Explanations"

This project was reviewed on

Mar. 08, 2011

by

Full Review
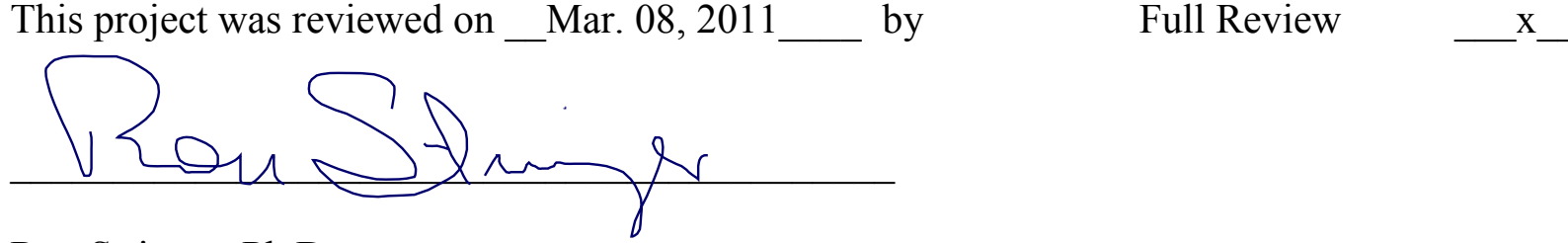

Ron Stringer, Ph.D.

Chair, REB II

Approval Period: 03 May 2011 to 02 May 2012

This project was reviewed and approved in accordance with the requirements of the McGill University Policy on the Ethical Conduct of Research Involving Human Subjects and with the Tri-Council Policy Statement: Ethical Conduct for Research Involving Humans.

* All research involving human participants requires review on an annual basis. A Request for Renewal form should be submitted 2-3 weeks before the above expiry date.

* When a project has been completed or terminated a Study Closure form must be submitted.

* Should any modification or other unanticipated development occur before the next required review, the REB must be informed and any modification can't be initiated until approval is received. 


\section{Appendix D}

\section{Interview Guide}

You told me that you are now receiving support at (Name of organization) for a sexual abuse experience you had in your childhood.

What prompted you to seek help about the abuse at this time and with this organization? Why? What happened or changed? How positive or negative was this experience for you? Was it the first time you disclosed the abuse?

\section{If YES}

What could have helped you to disclose before?

Were there other attempts to disclose? Help requested? Services sought? Is there any person you wished you had told? Move to concluding remark

\section{If NO}

Tell me about another time you disclosed. Who did you disclose to? What was different about this time? What led to the disclosure? How positive or negative was this experience for you?

Were there other attempts?

(Re-start question list under "If NO" until exhaustion of disclosures and/or attempts)

What could have helped you through the experience?

Move to the concluding remark

Concluding remark Is there anything else that you would like us to know? How do you currently feel?

Thank you, please contact us if you have any questions or comments about the interview or the research process; if you need support or referral because of what was discuss in the interview, I strongly encourage you to contact (name of worker) of (name of organization) at (contact info).

Risk assessment (if needed). 


\section{Appendix E}

Table 1: Participant information

\begin{tabular}{|c|c|c|c|c|c|c|}
\hline Participants & Age & $\begin{array}{l}\text { Age abuse } \\
\text { started }\end{array}$ & Abuser & $\begin{array}{l}\text { Disclosed in } \\
\text { childhood }\end{array}$ & $\begin{array}{l}\text { Age of first } \\
\text { disclosure }^{*}\end{array}$ & $\begin{array}{l}\text { First person they } \\
\text { disclosed to }\end{array}$ \\
\hline Richard & 55 & $\begin{array}{ll}- & \text { Age } 4 \\
- & \text { Late } \\
& \text { adolescents }\end{array}$ & $\begin{array}{ll}\text { - } & \text { Male } \\
\text { neighbor } \\
\text { - } & \text { Professional } \\
\text { at training } \\
\text { school }\end{array}$ & Attempt & 48 & OPP officer \\
\hline Jacob & 67 & Not mentioned & Family member & No & Late $40 \mathrm{~s}$ & Wife (now ex) \\
\hline Robert & 49 & $\begin{array}{l}\text { Starting at age } \\
7\end{array}$ & Eldest sister & No & 22 & Brother \\
\hline Sam & 58 & $\begin{array}{l}\text { Starting at age } \\
11\end{array}$ & Older brother & $\begin{array}{l}\text { No } \\
\text { (Sister } \\
\text { disclosed } \\
\text { twice - abuse } \\
\text { continued) }\end{array}$ & 50 & Wife \\
\hline James & 33 & Teenager & $\begin{array}{l}\text { Supervisor at } \\
\text { Camp where he } \\
\text { worked }\end{array}$ & No & 22 & Counselor \\
\hline Martin & 38 & Ages 2 to 11 & $\begin{array}{l}\text { Father } \\
\text { (adoptive) }\end{array}$ & Yes & 11 & Mother (adoptive \\
\hline Serge & 41 & Ages 13 to 14 & $\begin{array}{ll} & \text { Male } \\
& \text { neighbor } \\
\text { - } & \text { Older } \\
& \text { teenager } \\
\end{array}$ & Attempts & 25 & $\begin{array}{l}\text { Counselor during } \\
\text { domestic abuse } \\
\text { treatment }\end{array}$ \\
\hline Christophe & 27 & Age 7 & Uncle & No & 24 & Female friend \\
\hline Ted & 60 & Age 8 & Male neighbor & No & $\begin{array}{l}\text { Not } \\
\text { mentioned }\end{array}$ & Brother \\
\hline Jeremy & 56 & Ages 14 to 18 & $\begin{array}{l}\text { Girlfriend's } \\
\text { mother }\end{array}$ & No & Early 50s & Wife \\
\hline Mike $^{* *}$ & 48 & $\begin{array}{l}\text { Started in } \\
\text { childhood }\end{array}$ & $\begin{array}{l}\text { Multiple abusers } \\
\text { (both male and } \\
\text { female) }\end{array}$ & Yes & 10 & $\begin{array}{l}\text { To childhood } \\
\text { friend }\end{array}$ \\
\hline Daniel & 47 & Age 9 & $\begin{array}{l}\text { Family } \\
\text { acquaintance }\end{array}$ & No & Early 20s & Girlfriend \\
\hline Mario & 45 & Not mentioned & Stranger & Yes & $\begin{array}{l}\text { Not } \\
\text { mentioned }\end{array}$ & Parents \\
\hline Jean-Marc & 55 & Age 10 & Brother in-law & No & 22 & Friends \\
\hline Ben & 61 & Not mentioned & Not mentioned & No & $\begin{array}{l}\text { Not } \\
\text { mentioned }\end{array}$ & Counselor \\
\hline Simon & 46 & Not mentioned & Mother & No & 40 & Psychologist \\
\hline Philip & 19 & Age 6 & Male babysitter & Yes & 7 & Mother \\
\hline
\end{tabular}

* Approximate age

** Refused to be recorded 